\title{
A Discussion of Art Therapy Approaches Used in Classroom Activities to Help Students with Emotional and Behavioral Issues
}

Ashley Nichol Elliott

Follow this and additional works at: https://researchrepository.wvu.edu/etd

\section{Recommended Citation}

Elliott, Ashley Nichol, "A Discussion of Art Therapy Approaches Used in Classroom Activities to Help Students with Emotional and Behavioral Issues" (2017). Graduate Theses, Dissertations, and Problem Reports. 5538.

https://researchrepository.wvu.edu/etd/5538

This Thesis is protected by copyright and/or related rights. It has been brought to you by the The Research Repository @ WVU with permission from the rights-holder(s). You are free to use this Thesis in any way that is permitted by the copyright and related rights legislation that applies to your use. For other uses you must obtain permission from the rights-holder(s) directly, unless additional rights are indicated by a Creative Commons license in the record and/ or on the work itself. This Thesis has been accepted for inclusion in WVU Graduate Theses, Dissertations, and Problem Reports collection by an authorized administrator of The Research Repository @ WVU. For more information, please contact researchrepository@mail.wvu.edu. 


\title{
A Discussion of Art Therapy Approaches Used in Classroom Activities to Help Students with Emotional and Behavioral Issues
}

\author{
Ashley Nichol Elliott
}

Thesis submitted

to the College of Creative Arts

at West Virginia University

In partial fulfillment of the requirements for the degree of

Masters of Art

Art Education West Virginia University School of Art \& Design

\author{
Terese Giobbia, Ph.D., Chair \\ Alexandra Hollo, Ph.D., BCBA-D \\ Dylan Collins, MFA, MA \\ Department of Art Education
}

Morgantown, West Virginia 2017

Keywords: Art therapy approaches used in classroom activities. Copyright 2017 Ashley Nichol Elliott 


\title{
ABSTRACT \\ A Discussion of Art Therapy Approaches Used in Classroom Activities to Help Students with Emotional and Behavioral Issues
}

\author{
Ashley Nichol Elliott
}

The purpose of this paper was to inform the reader of the benefits of using art therapy activities in art lessons as a way to help students' process emotional and behavioral issues. New and future art educators are not equipped to handle the wide range of issues that students face everyday. This is especially true for the students in the West Virginia public school system. As in larger, more urban locations, many students here deal with drugs, violence, bullying, abuse, and others contemporary social stressors. In this paper, I utilized my own personal experiences, literary research, experimentation, and observations of others art therapy activities to discuss ways in which these art therapy activities could be used within art lessons, specifically in the K-12 classroom. The lessons I formulated used three specific activities: HTP (house, tree, and person), color therapy, and action painting. My lessons were a combination of art making, art history, and art therapy. These lessons may be important for future art educators to use when gaining insight into their students lives and personalities.

My own lived experiences while working with clients at a health facility in urban West Virginian, coupled with art therapy courses I took during my graduate studies, led me to research what art therapy activities I could incorporate into my future art classroom. During my last year of my graduate studies I was able to conduct lessons using the activities, I learned during my art therapy courses. I also was able to observe counselors, social workers, practicing art teachers and art therapy professionals using the art therapy activities and other creative therapies during sessions. For my research I covered specifically the 3 approaches of art therapy: HTP, Action Painting, and Color Therapy. I briefly identified how art therapy could help students in different stages of their lives,--how it affects their minds, helps them form alliances, and the teacher knowledge gained? When dealing with special populations. I was able to incorporate some of these activities into my lesson plans. Throughout this paper, I reflected on how these activities could potentially help students cope with stress and trauma.

Within each lesson, I also suggest solutions and further research on how to use art therapy in the public schools to help students. While more research is needed to prove that art therapy activities in art education lessons can benefit students with emotional and behavioral issues, I found through my own lived experiences that students were able to feel safe and comfortable during these art-making processes to communicate their problems to the teacher in order to start the healing process. 


\section{ACKNOWLEDGEMENT}

I want to thank my committee member for their patience and guidance throughout this journey: my chairs Dr. Terese Giobbia, as well as Professor Dylan Collins and Dr. Alexandra Hollo. I am grateful to Dr.Terese Giobbia for her knowledge and support throughout this writing process. I would also I to thank Dr. Giobbia for challenging me to be prepared to go into the art education field. I would like to thank Professor Dylan Collins for letting me explore new mediums in sculpture. I would also like to thank him for showing me how to be a fun, exciting, and positive teacher in the classroom. I would also like to thank Dr. Alexandra Hollo for taking the time to be on my committee and for her work with children with behavioral disorders. I would also like to thank West Virginia University Art and Design Program for giving me the tools I needed in order to grow both as an artist and educator. I would also like to thank the wonderful students, professors, teachers, administrators, social workers, and counselors I met during my observations.

I want to acknowledge my family for their lifetime of support: William E., Beverly J. and Jake E Elliott. I also want to acknowledge my grandparents for their lifetime of wisdom that I will not take for granted: Carl F., Loretta M. Elliott and Herbert V., and Sarah Galland. I also want to dedicate this paper to all the wonderful teachers I had growing up that allowed me to use my creativity when I was in a dark place in my life. 


\section{TABLE OF CONTENTS}

Acknowledgments ........................................................................................iii

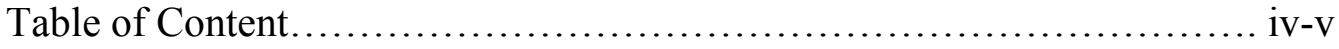

List of Figures..................................................... vi

List of Tables........................................................... .

Bibliography................................................ vii

CHAPTER 1 -INTRODUCTION ............................................................................p.1

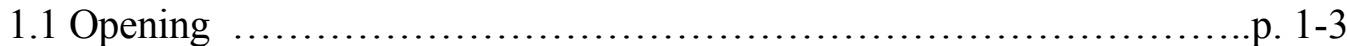

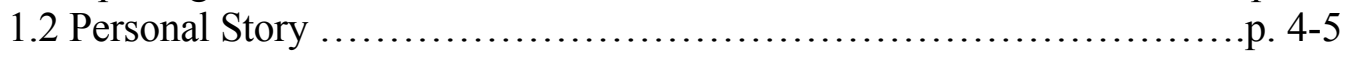

1.3 Paper Questions............................................... 6

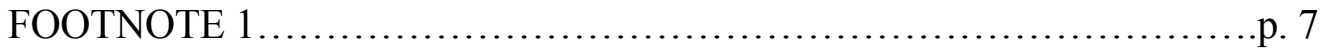

1.4 Brief Summary of Art and Process................................... $6-8$

1.5 Closing Thoughts on Chapter One..................................p. 9

CHAPTER 2- LITERATURE REVIEW ..............................p. 10

2.1 Color Therapy....................................................... 10

2.2 Action Painting- Techinques and Practices...........................p. 13

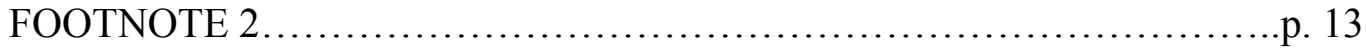

2.3 HTP Assessment.................................................... 14-16

2.4 Child's Art Therapy................................................. 16-18

2.5 Neuroscience Connection to Art Therapy................................p.19-21

2.6 Art Therapy Research and Findings with Children........................p. 21-25

2.7 Alliances in Art Therapy............................................. 26-27

2.8. Art Teachers Knowledge and Preparedness.............................p.27-29

2.9 Art Therapy with Autism.............................................p. 29-31

2.10 Art Therapy with Depression........................................p. 31-34

2.11 Art Therapy Importance on Children Mental Health Awareness Day.......p. 34-37

2.12 Art Therapy for Children of Hurrican Katrina..............................p. 37-39

2.13 Art Therapy in the Unitted States....................................p. 39-41

2.14 Superheroes and Emotional Intelligence.............................p. 41-46

CHAPTER 3 - PHENOMENOLOGICAL PAPER............................p. 47

3.1 The Phenomenon...................................................p. 47-48

3.2 Forming the HTP Lesson............................................ 48.49

3.3 Forming the Color Therapy Lesson......................................p. 49-50

3.4 Forming the Action Painting Lesson.................................... $50-51$

CHAPTER 4 - DATA ANALYSIS........................................p. 52

4.1 Introduction to the Findings.............................................. $52-53$

4.2 Site A - HTP................................................... $53-58$ 
4.3 Site B - Pastel Color Therapy ......................................... .p. 62-66

4.4 Site C - World Café Action Painting......................................... $72-74$

4.5 Site B - Girl Power Lunch Session......................................... $79-81$

4.6 Site B - Play Therapy with Special Education Class...........................p. 82-84

4.7 Site B - Students Interaction with Senior Patients..........................p. 84-86

4.8 Site D- Observation......................................................... 86

4.9 Site C - Counselor Observation........................................... 95-97

CHAPTER 5 - DISCUSSION AND FINDINGS............................. 99

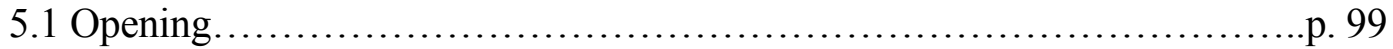

5.2 Summary of the Findings.................................................. 99-100

5.3 Reflection and Findings to Site A - HTP Lesson..............................p. 100-101

5.4 Suggestions for HTP Lesson................................................ 101

5.5 Finding and Reflection on Color Pastel Lesson - Site B........................ 102-103

5.6 Suggestions for Color Therapy Lesson.....................................p. 104

5.7 Site C - Action Painting Reflections and Findings..........................p. 104-105

5.8 Site C- Suggestions for Action Painting..................................p. 105

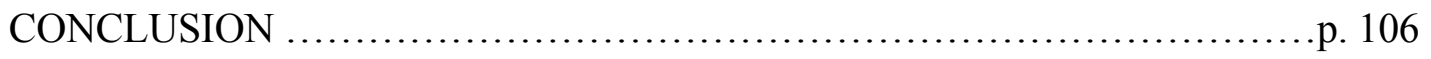

Suggestions and Future Research........................................ 106-108 


\section{LIST OF FIGURES}

Figure 1 Site A - Teacher Example HTP ................................p.58

Figure 2 Site A - Student Example of "Black River"............................p.59

Figure 3 Site A - Student Example "Ice Cream House".........................p. 60

Figure 4 Site A - Student Example of "Swarming Birds" $\ldots \ldots \ldots \ldots \ldots \ldots \ldots \ldots \ldots . . \ldots 1$

Figure 5 Site B - Teacher Example Georgia O'Keeffe Color Therapy................ 67

Figure 6 Site B - Blending Technique Example............................ 68

Figure 7 Site B - Student Example "Rose with Cop Car Lights"................ p. 69

Figure 8 Site B - Student Example "Breast Cancer Bull Skull”..................p. 70

Figure 9 Site B - Student Example "Lack of Color" ..........................p. 71

Figure 10 Site $C$ - Action Painting Teacher Display Board.................... 75

Figure 11 Site $\mathrm{C}$ - Student Experiment Blending Drips...................... 76

Figure 12 Site C - Students experiment with Controlled Movements ..............p. 77

Figure 13 Site $\mathrm{C}-$ Students Work Drying.................................... 78

Figure 14 Site D - Coloring Activity..................................... 98

Figure 15 Site B -Student Experiments with Pastel Dust.......................p. 103 


\section{LIST OF TABLES}

Table 1. Color Therapy: Color, Location, and Power................................p. 11

Bibliography ................................................. $109-111$ 


\section{H A P T E R 1: I N T R O D U C T I O N}

\subsection{Opening}

In the state of West Virginia as in many other states across the United States, art educators are not always prepared to deal with issues that affect students' emotional and psychological well-being. The current educational system is so concerned with standardized test scores they sometimes forget today's students are dealing with challenging societal issues. While most public schools do have master level therapists to help students deal with some of these issues, it is overwhelming to think about how much each of these counselors have to deal with during the course of the day. With thirty or more students dealing with life stressors such as traumatic experiences at home or in the community or mild, moderate, or severe disabilities, and students that just need a little more attention, even the most experienced public art teachers cannot handle the diverse needs of all their students in a 45-50 minute time frame. As a result, most art educators are not prepared to deal with these overwhelming issues with their students. Depending on the program art education students are required to take education and special education classes, however many of these classes don't go into details about what art activities you can use with such a wide range of students to them cope with struggles they face due to personal or environmental factors.

What qualifies one to be an art therapist verses an art educator? An art therapist is a professional health provider who uses the arts as a means of communication and support. The art projects that the therapist conduct allow the patient to create art, and during this art making process the patient can start to open up to the therapist in order to 
start the healing process. This art can lead to better socialization, ease stress, less pain, cope with loss, improve both cognitive and motor skills, and increase their sense of empowerment ("Art Therapy \& Autism," 2017). In order to be an art therapist, one must be recognized by the Art Therapy Credentials Board, and have obtained the proper credential: ATR (Registered Art Therapist), ATR-BC (Board Certified Art Therapist), and ATCS (Art Therapist Certified Supervisor). There are currently approximately five thousand art therapists around the world in the field today.

An art educator is a trained artist in a specific medium or several mediums that share their knowledge in an academic sense. The art educator demonstrates how to use certain art materials, covers art movements, history, and challenge their students in higher level thinking while creating a piece of work. During many art educators' teaching careers they notice that many students while creating art will open up to the teacher in a personal and emotional way, which leads to art being used as a therapeutic tool to connect with their students. I have witnessed art educators that have retired from art education and go towards getting their license to practice art therapy.

There is currently a gap in the literature that discusses how art teachers should prepare to teach students with a wide range of disabilities as few, if any, studies have been published in the last nineteen years regarding this (Coleman, Cramer, Park, \& Bell, 2015). Many teachers feel they lack the knowledge and skills to teach students with emotional issues and physical disabilities (Coleman, Cramer, Park, \& Bell, 2015). As a result, West Virginia schools need to find more creative and substantial ways to deal with the emotional and psychological well-being of adolescents and adults in their classrooms and discover new ways to use art in the classroom may help to solve more of these 
societal problems. This paper discusses some of my personal experiences observing students in school settings and clients in clinical settings who are attempting to deal with emotional trauma.

As part of my graduate studies, I observed students in the suicide wing at a rehabilitation clinic. Some of these students were diagnosed with extreme depression and had attempted suicide several times. Through my own personal experience of working as a Behavioral Tech in a health center in urban West Virginia, I observed first hand children as young as eleven years old getting rehabilitation treatment for methamphetamine use. This same health center also had an after school junior AA program where usually a dozen or so junior high and high school students showed up to regularly attend meetings. As a pre-service art educator, I also noticed during my student teaching that many students in the classes I worked with struggled to cope with issues such as drugs, emotional and physical abuse, suicide, bullying, depression, and many other difficult experiences. The lack of training on these issues and the lack of special education aides are also very concerning and lead me to think about ways to incorporate more meaningful instructional strategies I could eventually use in my classroom. The strategies referenced in this paper are based on my own personal observations of what other teachers and art therapists have used as a way to deal with some of these issues and thus became a way for me to think about ways to improve my own teaching for future use in the classroom. 


\subsection{Personal Story}

My own lived experiences demonstrate just how art helped me when I was dealing with my emotional problems, and helped my overall well-being. As a young child I had speech therapy, I lived in a very rural community in Wood County West Virginia and didn't develop my language skills due to a lack of interaction with other people. I remember my speech therapist asking me to draw pictures of things I wanted to say, and then we would practice saying the words by using fun interactive games. I had speech therapy until I was in the third grade.

During elementary school I was always bigger than the other students both in height and weight. I was bullied to a degree that I started to lose weight at a rapid rate. By the age of thirteen I had developed anorexia and my lowest weight was one hundred and three pounds, around thirty pounds underweight. I remember being cold and low on energy and always wanting to sleep. I wore a jacket with a hood to cover my face, even when it was ninety degrees outside, I didn't want people to see how fat and ugly I was. It always seemed like eyes were on me, judging every imperfection on my body. I thought about suicide, but never attempted it, perhaps it was because of my religious upbringing and the thought I would be damned if I took my life. When my mind went into dark thoughts I remember drawing in my sketchpad. I would draw to help me not think about taking my life, and get the dark thoughts out of my mind before they swallowed me up.

My parents provided me with a therapist. I remember the therapist asking me to draw a house, then a tree, and then a person. I took my time and drew a realistic house and an oak tree with green leaves. The person I drew was a Barbie like figure in the foreground, because I thought that is what the perfect body should look like. Then the 
therapist asked me to describe the house, the tree, and then the person. I didn't know it at the time, but when I was taking my art therapy classes in graduate school, I realized I was giving the therapist an insight into my personality.

I went to see the therapist a couple of times, but what really helped me was my junior high school art and science teacher. In science class we learned about the human body and nutrition, it finally dawned on me the damage I was doing to my body. My art teacher allowed me to express my creativity, and always gave me extra assignments to challenge myself. Later in junior high my art teacher entered my work in local art competitions. She also let me be her art assistant and allowed me to be the teacher and go around and help other students with assignments. By then I was taking honor choir and piano, which helped me get back on track with my health and mental health.

In high school I joined theater; this helped me get my confidence back, and helped me with getting comfortable with people again. Theatre also helped me escape reality, as I could be whoever I wanted to be. These teachers from my past focused on my strengths rather than my weaknesses, and allowed me to express myself. I was lucky to have family, a therapist, and excellent teachers to help me heal my mental health through the arts; however many West Virginia students are not so lucky. My own lived experiences and observations have lead me to believe that using art therapy approaches may provide classroom art teachers with tools needed to help others students who are dealing with similar types of issues deal with their own problems, or at least give the teachers an insight of what the student is dealing with and can begin to address the problem. 


\subsection{Paper Questions}

In this assignment I observed how three different art therapy approaches-color therapy; HTP and action painting, within the school curriculum appeared to help students deal with some of their own emotional and behavioral issues. I will discuss the three approaches I observed and examine how one art therapist and two teachers used these approaches with students. I then discuss the visual outcomes of these approaches used by therapists and art educators.

\subsection{Brief Summary of Art Therapy \& Processes}

Art therapy is a combination of deep understanding of the arts, as well as an equal understanding of psychology. In its true nature form, it is both an assessment as well as a treatment for the individual and as such can be used in a multitude of ways for both assessment and for therapy, benefiting a diverse population of clients. Elinor Ulman, one of the pioneers of art therapy stated, "Art therapy is to be a procedure designed to assist favorable personality changes or living that will outlast the session itself' (Rubin, 2010, p. 25). Yet, today there is still confusion between professional art therapists, and those who use the arts as a therapeutic activity. Throughout my observations of practicing art therapists and art educators in my graduate school program, I only observed counselors and the use of the arts as a therapeutic activity.

The goal for any art therapist is to aid in understanding, as well help the client grow in change. My goal as an art educator is to teach an art skill, but also have my students achieve a higher level of feeling, broadening their sense of self-esteem, and expressing ideas that may be hard for them to communicate through words. In both fields, painting is a useful art therapy medium for everyone. Students as well as adults can 
experiment with a wide variety of paints, tools to apply the paint, and movements, but how do you keep the painting studio structured with a large group? During my student teaching experience, I conducted just such a lesson at Site C high school in rural West Virginia, using Jackson Pollock splatter paintings. This was held during the school's World Cafe event ${ }^{1}$. I had a diverse population of students who signed up for an after school class held outside of the art classroom. Students were able to freely express emotions through movement painting just using everyday tools to apply the latex paint in a controlled outside environment.

The House, Tree, Person (HTP) is also a useful assessment tool. The HTP assessment gives the therapist or art therapist insight into the patient's subconscious. The house, tree, and person, depending on how the patient drew the objects and placement on the paper, can determine a lot about the patient's personality. For example if the roots are showing on the tree, it might mean the patient is grounded and secure in its current surroundings (Frankish, 2015). Then the test can be given over again to see if there has been any progress. During my art therapy classes I developed a lesson using the HTP test to assess the children at Site A in a government facility in rural West Virginia. During this lesson I gave them the objective of painting one house, one tree, and one person. I did not give details of what all three of the elements meant, but rather gave them the basics. I gave students demonstrations and visual aids for how to form the human body,

\footnotetext{
1 World Cafe is an annual event hosted by the Art Club at Site C in a rural high school in West Virginia. This event first started out as a dance and field day for the students before finals. The Art Club felt there needed to be an art and culture day for the students, and the community to takes part in this event. Local business, organizations, and special speakers come in to volunteer to teach a class. Some of these classes included Native American dancing, English poetry tea time, and Henna hand tattoos. I was one of those volunteers, and designed a lesson using action painting. I had six classes with around 25 to 30 students in each class; this lesson was held outside of the art classroom. Students were able to freely express emotions through movement painting just using everyday tools to apply the latex paint in a controlled outside environment.
} 
house forms, and tree forms, and how to use watercolor materials. Later in this paper I will discuss my findings later offering opinion as to whether an HTP assessment might be successful in the public classroom setting.

In contemporary society we are surrounded by black or grey buildings with very little color. Color therapy would be a great assessment tool to use while introducing the color wheel to art classes. Introducing more colors in the school hallways and other classrooms may also improve student's mental health and well-being. While I was student teaching in the middle and high school placements in rural West Virginia, the hallways were always bare. The only rooms with color were the art classrooms. When I was observing at a facility that dealt with students with cognitive challenges, the rooms and whole building were somber beige. The lack of color encouraged me to use a lesson plan at my middle school placement where I had students create a color abstraction lesson using pastels, using the artist Georgia O'Keeffe for inspiration. Artist such as O'Keeffe and Rothko often dealt with experimentation with color and abstraction. Throughout my lesson I observed different color combinations the students were using and made the predictions on how students were feeling by the colors they used. One student used colors to describe an event he witnessed at home. The high school teacher decided to do the same lesson with her classes using oil pastels and I also observed the colors the students were using to determine color combinations. 


\subsection{Closing Thoughts for Chapter One}

West Virginia students are dealing with many societal issues that are real and troubling. Our current educational system does not prepare our new upcoming art teachers to deal with these problems within the schools and art classrooms. My paper suggests programs attempt to better prepare our new and upcoming art teachers with tools, strategies and activities that are more in keeping with contemporary societal problems that we now face in the schools in West Virginia. We need new and creative approaches that will aid educators in dealing with students who are struggling with these issues in their art classrooms; we need new and creative art therapy approaches to help to bridge the gap. 


\section{CHAPTER 2: LITERATURE REVIEW}

\subsection{Color Therapy}

This chapter discusses the three art therapy approaches, those being color therapy, action painting and HTP, which formed the basis of my lesson plans discussed later in this paper. Color therapy has many benefits for emotional, spiritual, and medical health. In many urban settings we are surrounded by a grey landscape, and the human eye and brain needs color to process our moods. Color can balance and restore the body by absorbing light energy through the sun (“Color of Healing”, 2017).

The human body responds to colors differently. For example if you are a person who responds to warm colors such as red, oranges, and yellows, you may need cool colors such as blue and greens to balance your body energies. Colors in the classroom and art projects may be used to re-balance physical, emotional, and mental deficiencies in our students' daily lives. Each color has both a positive and negative affect in your body; it depends on how you use that energy. Each color affects different parts of your body, better known as Chakras. Chakra originated in India, and is connected to the origin of Yoga; Yoga is the union with the mind/body and divine consciousness (Brocas, 2006, 
para.1\&2). The chart below describes the colors, location on the body, and power behind color. Table 1 below describes the colors, location on the body, and power behind color.

\begin{tabular}{|l|l|l|}
\hline \multicolumn{1}{|c|}{ Color } & \multicolumn{1}{c|}{ Location on Body } & \multicolumn{1}{c|}{ Power } \\
\hline Violet & Crown & $\begin{array}{l}\text { Higher Reasoning, inner } \\
\text { wisdom }\end{array}$ \\
\hline Dark Blue/Indigo & Brow/third eye & Vision, Awareness \\
\hline Light Blue & Throat & $\begin{array}{l}\text { Communication, self } \\
\text { expression }\end{array}$ \\
\hline Green & Heart & Love, Compassion \\
\hline Yellow & Abdomen/solar plexus & Power, Willpower \\
\hline Orange & Reproductive Organs/sacral & Creativity, emotions \\
\hline Red & Spin, Legs/Root & $\begin{array}{l}\text { Survival, nourishment, } \\
\text { grounded }\end{array}$ \\
\hline
\end{tabular}

Table 1. Color Therapy: Color, Location, and Power ("Color of Healing", 2017)

In color therapy patients are given colors for healing purposes by a trained color therapist. The therapist uses color wheels, colored light, crystals, colored oils, tonics, color acupuncture, or breathing in colors through the use of meditation. The therapist's goal is to keep the colors within the mind and body balanced for overall good health. Color therapy is surprisingly effective to relieve stress and traumatic memories ("Color of Healing", 2017). One therapist in the film retold a situation about a young female client who wanted to be more social and creative. The therapist discovered the client was lacking orange in her body. The therapist at first tried to introduce orange, but client 
refused. Orange is a warm, creative, and emotional color. After six weeks of orange color therapy client became more social and outgoing ("Color of Healing").

Color therapy is the combination of both the therapists and client using their energies, thoughts, and colors to determine what the patients' needs in order to have a balanced body. In the art classroom, teachers would not have a light crystal to find out what color the student is lacking. However the film "Color of Healing" mentions that energy is released through the fingers, so perhaps the students could release color energy in classroom projects. The film also mentions that at home you can use meditation, visualize a color, or express a color you need in your life by wearing it ("Color of Healing"). This film is very knowledgeable in the psychotherapy of color therapy, however there is little evidence to back up their finding. This film was an introduction of another creative therapy that can be used to improve health in a spiritual way.

During my observations I noticed a lot of children wearing odd color combinations. This could have been a fashion trend, or perhaps this was a subtle message of what colors they were lacking in their lives. With the 6th grade class I wanted to do a lesson experimenting with colors. I also wanted to see if students would use a pattern of repeated color combinations to support if they were lacking color, or they would use color to express something happening in their lives. In the color lesson I conducted at Site B, I will determine if color therapy in the classroom is successful at determining if the student uses color to express to the teacher if something is lacking or happening in their lives. . 


\subsection{Action Painting - Techniques and Applications}

According to studies done on art therapy techniques and applications, painting is a useful art therapy medium for students and all clients. Buchalter also states that, "painting allows for freedom and experimentation. That students and other participants can experiment with color, style, and movement" (Buchalter, 2009, p. 98). A multitude of painting materials can be used in painting therapy such as watercolor, acrylic, tempera, finger-paint, etc. When it comes to watercolor the client can have more control when making the medium dark, light, thick, thin, and adding more or less water. Watercolor is usually easy to clean up (depending on the age of the client, and if the client has used the medium before), and watercolor can be painted over pre drawn outlines (Buchalter, 2009, p. 98). With acrylic it takes more skill and practice, it does dry quickly and easy to clean up. Also with acrylic you can overlap and blend the colors easily. Buchalter suggests that when using flick or action painting like the works of Jackson Pollock that it would work best in a very structured environment with high functioning clients or students (Buchalter, 2009, p. 98). In Buchalter writings she does not mention using latex house paint like I did in my lesson using Jackson Pollock; however I agree that using a non toxic paint medium would be safest when dealing with younger students and students with special needs. For example if you had a student with Pica $^{2}$.In my action painting lesson, I had upper level high school students and felt they were capable of using the latex paint. While this text is very informative, however this only applies to a controlled

\footnotetext{
${ }^{2}$ While I was working as a Health Tech at a health facility in urban West Virginia, I worked with a client that had Pica. Pica is an eating disorder where the client eats non edible objects. With a student with Pica, I suggest lessons that use non toxic materials.
} 
art therapy session. Would these methods apply to the public art education as well, given a controlled and structured environment?

\subsection{HTP Assessment}

Frankish likes using the HTP assessment with children because of its simplicity. The house, tree, person test can be given to children, adults, and clients with special needs. In an HTP assessment it is more successful if the client does not linger on drawing or painting the objects, the reason being that we draw what firsts pops in our subconscious(Frankish,2015,p.74). The house, tree, and person represent a different element to the student or client taking the test. The house represents if you are grounded and their basic sense of security. The tree represents the life force or ego of the client. The person is the overall identity and sense of self. It is very important that the client does not know they are going to take the HTP assessment or the results will be invalid (Frankish, 2015, p. 75). In a group setting the client must not feel like it's a competition or they will feel discouraged and not carry on in the assessment" (Frankish, 2015, p. 76). Once the client is done making the HTP it is put away and taken over again at a later time. The therapist or the therapist plus client can analysis both drawings and see if there was any growth or change in the drawings. The house represents if the person is ground and their sense of security. Different parts of the house may indicate different parts like having lots of windows maybe could indicate signs of abuse. No door could imply the client feels trapped, or can't get into the home. For the tree it's a symbol of life force and ego. For clients with intellectual disabilities many draw a tree with a stunted trunk, or limited top. Clients that have not roots on the tree maybe have cut themselves off from the past. Some clients add extra features like birds, fruit, or a hole in the trunk as a 
symbol of sexuality. (Frankish, 2015, p. 76). The person in the HTP represents how the client views themselves, and according to Frankish even if the client draws a stick figure it gives the therapist insight about how the client views themselves (Frankish, 2015, p. 77). Some patients will draw themselves as a monster or some kind of other creature because that is how they truly see themselves. Some patients draw a whole recognizable human form, which is a sign of the client viewing themselves as a whole person. In my drawing I did of the HPT when I first went to see a therapist I drew myself as a Barbie doll. This could have meant I saw this as the perfect female body, or I was myself as merely an object or toy, which sometimes can initiate as a symbol of youth and innocence. With patients that are offenders or have committed some sort of crime, they will usually draw only the head, because they defy their own bodies and don't want to face what they have done (Frankish, 2015, p.77). Then you look at the house, tree, and person all together. If the client draws a strong tree with a good structured house, but a tiny person, this is an example of a good early development, however something happened to the ego to make the person feel like they are tiny and insignificant (Frankish, 2015,p.77). Frankish conducted the HTP assessment with several controlled groups including a group with disabilities, she claims that she was able to get information quickly through the HTP assessment in order to focus on the problem and start treatment (Frankish, 2015, p. 78).

While this information was useful, it was conducted by a therapist in a controlled environment. Could the HTP assessment be done in a public school setting through k-12? Even more importantly, could I do this assessment without breaking confidentiality and also utilize the West Virginia education CSO's with art therapy in the classroom? 
Thinking about these questions, I conducted my own HTP assessment with a group of young children at a government facility in rural West Virginia and will discuss later in this paper if the HTP assessment would be successful in the public classroom setting.

\subsection{Child's Art Therapy}

As a psychotherapist, Rubin was drawn to what could not be seen in children's minds. Art gave her the chance to look for the forbidden. Art was like "private feelings made into public form" (Rubin, 2005, p. 58). In her book Child's Art Therapy, Rubin examines her own uses of art therapy in her personal life. She retells how art helped her cope with her best friend's sudden death when she was seventeen years old. She went into the woods and started to paint, the figure was that of a man crying and playing the piano, and as she painted she realized the painting was symbolic of the friend she lost. Painting helped her deal with her rage and opened up other emotions to help her through the grieving process. Later when Rubin's daughter started having nightmares, drawing helped her daughter take control of her dreams. Rubin realized drawing gave her daughter peace of mind, "giving form to the feared objects brings it under your own symbolic control" (Rubin, 2005, p. 60).

Rubin examines the history of art therapy, and several pioneers' views of helping children through the arts. In the early developments of mental health, educators found the benefits of a freer artistic expression in the school system. During the 1950s educators were convinced that the arts and other creative experiences were vital to children's education and overall development (Rubin, 2005, p. 63). Within her discussion, she pays homage to Margaret Naumburg and Edith Kramer, significant pioneers in the field of art 
therapy. Both women had very different views about art therapy; however both of their methods are still used to this day.

Rubin covers different approaches in art therapy exploring materials; group settings; individual sessions, family and group sessions, art therapy activities everyone can participate in, and issues you may come across in art therapy dealing with children. For my review I will discuss Rubin's findings within her group sessions, since I will be dealing with a classroom. I also want to discover what problems I may come across when doing art therapy projects in the classroom.

In Rubin's early work with both children and adults group sessions. The emphasis was on the individual work in a group context, with perhaps a discussion of the product afterwards. Rubin describes how joint projects can be beneficial to the individual to experience their relationship within the group dynamic. Once you have a group session together, what kind of activities can you do with that session? According to Rubin, "For older children warm-up activities or specific tasks may ease their adjustment to unfamiliar space and people" (Rubin, 2005, p. 327). This is very true, in my personal experience I noticed it is hard to get adolescent students comfortable with each other. With group activities with classmates they don't socialize with it's very awkward at first. A lot of art teachers in the beginning of the year do ice breaker project or warm-up activities like Rubin suggests. For younger children having a mystery item, such as a "Feely-Meely Box," creates a sense of mystery and wonder for the group (Rubin, 2005, p. 327). Children will reach into box and describe what they feel and it becomes a great ice breaker activity for younger children (p. 327). Sometimes both children and adults will not know how to start a project, and giving the individual a "visual starter" for 
example, putting a blob of paint on paper, drawing a random line, or part of a photo, or anything to help the individual get past the block will help with the process (p. 327). In her section of children group therapy, Rubin discusses in detail experiences she has with children group in these sessions, covering how group members get to know one another, how the group grows over time, techniques for bringing structure into an unstructured group, themes and concerns when having a group session, creative therapies such as food and role playing in group sessions, and lastly the roles members take in a group session (Rubin, 2005).

Rubin experiences are insightful, and her work is a lot like the encounters I had while student teaching. I believe some of the projects such as the "Feely Meely" box would translate well in a young student demographic. Rubin also discusses her art therapy sessions with large special needs groups in hospital and institutions. Nevertheless, her research included group sessions conducted by an art therapist rather than lessons conducted in a K-12 classroom. The group I would find most challenging is the adolescent groups. Many adolescent groups are reluctant to share in group settings. Perhaps with an art lesson that all the group members have in common interest in would be a nice warm up art activity in order to start communication in the group.

While I appreciated Rubin's personal reflections especially her findings in the group sessions, I hope in my future teachings, I will be able to reflect how the class responds to the project in order for my class to grow as a group in art making. 


\subsection{Neuroscience Connection to Art Therapy}

Other researchers in the field of art therapy have used neuroscience as the center for understanding the mind-body connection, as an essential way to evaluate the use of art therapy as a mind-body intervention (Husky, 2009). Art therapy according to Husky has been used in the medical setting for a long time, and as a way to connect the mind and body for healing purposes. During her research Husky came across the work of Malchiodi (2005), who exposed a theory that "mind-body medicine is a popular term used to describe an approach that views the mind as having a central impact on the body's health" (Husky, 2009). Research on the field of art and the impact of its effectiveness on the mind and body has barely scratched the surface according to Husky. Her research revealed cases where researchers found conditions such as depression can affect the immune system and cause other negative conditions to the body. Husky proposed that art therapy can be used to medicate the mind as well as the body (Husky, 2009).

Husky felt that art therapy varied depending on the philosophical perspective. As a whole, art in the field of therapy is the process of making art therapeutic, thus the creative process is healing, leading to growth and discovery of self-expression. Art psychotherapy suggests that symbols in the art itself aides in communication between therapist and patient. Many hospitals have found that art can benefit one's health, which is why many hospitals and medical facilities are introducing art programs for patients to foster creativity (Husky, 2009). Hospitals have found that art programs help patients with pain, give the patient a sense of control in their current situation, foster self-expression, 
and most importantly give the patient a sense of well-being (Husky). Husky agrees that art is truly therapeutic; however we need to focus using art as a true therapy rather than being an activity or being well intended gesture by an artist. Husky suggests that, "art therapists need to be aware of current research, and bridge the arts and the science ways of knowing," meaning combining the arts and science together as a form of therapy (p.41).

Husky's theory goes in depth into how the brain works using theories based on other researchers work as a source and suggests that art therapists need to consider each patient's brain recognizing that what one symbol means to us might have an entirely different meaning to the patient (Husky, 2009; Riley, 2004). Therefore, Riley suggests that art therapists need to consider right and left brain theory, where the left brain mulls over intellectual intelligence with the right brain dealing with emotional intelligence (Husky; Riley). These particular studies discuss how neurons in your brain are fired up when introduced into a new situation or new stimuli. Over time the neurons form patterns and communicate to the body why they are having these reactions, leading the patient to have a greater understanding of the reaction. Understanding the basic functions of the brain is crucial to art therapists, with this knowledge we have a better understanding of the patient's 'language' (Husky, 2009).

In summary, there is a connection between the mind and the body whereby the mind can communicate to the body what it needs in order to be in balance (Husky, 2009). Art therapists encourage the patient to draw upon inner images to trigger the body's own healing processes. Art therapists are experts on how to let the patient know how to activate the left and right hemispheres in the brain to proceed in the mind-body responses 
to find symptoms in order to start the healing process. The lack of research in this field supports the need for more research needed on this subject, however "neuroscience has repainted a picture of how art therapy is used in the treatment of emotional and physical disorders in the future" (p. 68).

I am in agreement with Husky; I think there needs to be more research on how the right and left hemispheres of the brain responds while patients are creating art. This way therapists, doctors, and educators can have a better understanding of the human mind and know what art making projects to do in order for the healing process to start. I think it could be interesting to do a study with students and have their brains monitored for brainwave activity while doing different art projects. This will determine if the right or left hemisphere of the brain is communicating what the body needs in order to heal.

\subsection{Art Therapy Research and Findings with Children}

Other researchers, such as Gilroy inform the reader of current art therapy practices and research from clinical work. Projects range from microanalysis of interaction between clients, to processes in their art, and their therapists. Gilroy divides his book into three sections--findings with children; adults; and patients with disabilities (Gilroy, 2011). My discussion focuses on the research and findings Gilroy did with children.

In the chapter focusing on children, Gilroy conducted his experiment on a nine year old boy's artwork over a two year period. Gilroy wanted to discover if the art process in art therapy could lead to what happened to this child that caused him to miss the crucial stages in early childhood development. Gilroy used retrospective review, children drawing theory, and Jackson Pollock's art approaches. Gilroy's goal was to find a link 
between changes in the art process and a patient's development outside the therapy session (Gilroy, 2011).

Gilroy first noticed that children that were extremely damaged and children under less traumatic situations "rapidly responded to non-directive approaches to art therapy" (p.20). Children became interested in art materials and the art process itself seemed to have potential to fill avoid the children were missing in their early environments (Gilroy). One child puzzled Gilroy from his rapid change in the art therapy setting, despite his severe condition. This child, which Gilroy called 'Paul' had a rough upbringing.

"Paul's mother had extreme depression, and he lacked basic care. This leads to concerns of reaching milestones in early development. In school, Paul had poor literacy and mathematic skills; he also refused to take part in class. Paul would also react to small stressor such as his mother leaving to go to work. He would show signs of hyper arousal, would not respond to soothing, became detached, show on face expression, and would become aggressive with other children. Paul overall had no sense of himself “(p.20)

Gilroy wanted readers to know that as "art therapists we have to be sensitive to these children's states, often you will see mirroring activities rather than interpreting the early stages, or else promoting the beginning of a relationship" (p.21). Gilroy goes into the psychology between mothers in child in early development, and suggests using a maternal approach to form a relationship between art therapist and patient (Gilroy). Another point that Gilroy brings up is 
"These children lack of early development will lead them to not know how to interact with art and play materials, because they have not reached the stage of how to use their imaginations. The children will re-present a situation or feeling, rather than use symbols in their artwork to represent a feeling" (p.22)

Gilroy's hypothesis was the art process within art therapy was the key factor in the treatment of children with developmental deficits. In order to conduct this experiment with Paul, Gilroy used the following 4 stages based on Schaverien work:

1. Systematic analysis of shapes, form, color, and any other marks made in each picture 2. Documentation of change in the artwork.

3. Reference to change in therapeutic process as recorded in process notes.

4. Where the patients comments available, comparison notes between the patient and therapist experiences (Gilroy, 2011, p.26).

Paul created forty paintings on paper and a cupboard filled of containers of different mixtures. Gilroy noticed the art making process seemed more important to Paul then the finished product. Paul naturally took to the art making process, after a six months period he was hungry for more. The therapy seemed to be filling a need in him. Gilroy went ahead to see if his work showed signs of cognitive and emotional growth, and if he was including symbols in his work (p.27)

Gilroy researched early child drawing theories, and found Paul's work in his middle stages of therapy had a Jackson Pollock-like quality. Gilroy used Ehrenzweig's stages of creating a piece of work and demonstrated how she could use these stages at different points in Paul's therapy (Gilroy). Stages included:

1. Putting unconscious parts of the self into the work 
2. Unconscious integration on an undifferentiated manic level. (Emerging you into the work).

3. Picture is seen as having a separate existence (Gilroy, 2011, p.27).

Gilroy placed Paul's work in chronological order and took photos for documentation and easier viewing. Gilroy found Paul's work was all different, even if Paul used similar methods. Gilroy also noticed that Paul put a range of emotions into his marks. However, Gilroy was not able to determine these feeling because of Paul's lack of facial expressions. Paul did apply marks using full body motion and different material such as clay, and discovering making mono-prints or making mirror images with clay (Gilroy, 2011).

Gilroy's study revealed how Paul's early work was similar to that of a fourteen month old: meaning that repeating lines and motions lead to an awareness of effects of his actions, and he could experiment and control those actions. Gilroy presumed at Paul's experimentations with a variety of material was to find meaning and patterns in the world around him. Also seeing the impact of his movements and feelings made concrete in his work (Gilroy, 2011). In Paul's middle stage of artwork he was showing greater control, also showing an understanding of balance. Paul experimented with folding the paper with paint on it to create symmetry. Now Paul was coming up to Gilroy to show her his work, and his surprise and pride in his work. Paul was also putting ideas into his work and also giving them titles, leading to his growth of imagination. Paul started to put symbols of being deprived by his mother and get emerged into the piece, and then he would reflect on those symbols. By the end of the experiment Paul was less fearful and was doing 
better in his school environment. Paul was able to create and explore in a calm setting to discover his sense of self (Gilroy, 2011).

Gilroy concludes that using art therapy with young children allows them to be able to stimulate their creativity drive to engage in a developmental process.(Gilroy, 2011) Gilroy's main goal was to prove that interaction and engagement with art materials could offer children gratification and a sense of fulfillment (Gilroy). The author did find that "children can regress and find fulfilled and gratification in the use of tactile materials in spontaneous ways which help them discover a sense of agency" (p.34)

One thing I did not consider while I was reading this text is how art therapy can help children with the lack of early developmental skills. The issue I have with this text is that Gilroy's was over a gap of time; however he conducted the experiment with one, or few children. How would these art sessions and projects work with a large group of students with no early developmental skill? Nevertheless, I plan on using future lessons using the 4 stages of Schaverien and Ehrenzweig's 3 stages of creating art that Gilroy implemented when working with Paul. I have a feeling some of my students might lack early developmental skills and the art making projects that Gilroy used may be beneficial for them. 


\subsection{Alliances in Art Therapy}

Cliff Joseph held several positions as an art therapist in several mental institutions, having witness the process of diagnosis that determines mental illness. The majority of the diagnoses did not consider outside factors such as environmental conflicts, family, school, work, and etc. In this article Joseph mentions his patients dealt with a handful of outside conflicts such as poverty, homelessness, racism, sexism, and dealing with the arrogance of other people. This led his patients to feel like they were being alienated and insecure about themselves, this lead to mental health issues.

Joseph believed in the power of alliances, he "wanted his staff and patients to form therapeutic relationships" (Joseph, 2006, p.30). Joseph encouraged his staff to keep up with patient's history and what triggered positive and negative behaviors in his patients. This is where art therapy came into play, in that art the patient has created becomes reference for staff to build on the alliance they had with patients (Joseph, 2006). I agree with Joseph when forming alliances. Many art educators form close alliances with most of their students, and the student's work can become a blueprint toward the inner working of their feelings.

Joseph like many West Virginia students grew up in poverty, and dealt with a variety of environmental stressors. Like many teenagers Joseph did not identify with his family, and thought the world was against him, and therefore he formed few alliances. Later Joseph realized the struggles and stressors surrounding his environment. He started to form alliances with his family, friends, and teachers. Alliances for Joseph are a crucial way to survive in this world. After he formed these alliances, Joseph used the arts as a way to express his views of oppression of society (Joseph, 2006). When Joseph first 
became an art therapist, his experience with struggling to form alliances made him more relatable with the patients. After Joseph formed an alliance with a certain patient, they would start to identify problems and explore possible solutions (Joseph).

I agree with Joseph when it comes to forming alliances with your students. Many students may act like the lone wolf, but as an art educator you may be the only one that they trust. In my student teaching placement, my cooperating teacher told me I would be a person wearing many hats, meaning I would be their teacher, friend, therapist, parent, and sometimes the only ally they will ever have. I believe having a strong alliances with your school, faculty, school board, and community is also beneficial for looking out for students well being.

\subsection{Art Teachers Knowledge and Preparedness}

In the article, “Art Educators' Knowledge and Preparedness for Teaching Students with Physical, Visual, Severe, and Multiple Disabilities" (2015), the author examined teachers via an online test to see whether art teachers felt they were prepared to meet the needs of students with physical, visual, severe, and multiple disabilities (PVSMD) Seventy-seven art educators from pre-K through $12^{\text {th }}$ grades participated in this test (Cramer, Coleman, Park, Bell \& Coles, 2015). The article briefly describes the history of inclusion movements, and disability rights. While the authors of art education journals and books believe that education has made stride in instructional practices when working with students with disabilities, the data from this article shows that art teachers feel less prepared than ever. And while most general education teachers felt they understood the characteristics of special needs students and used both effective behavioral and assessment strategies, art educators felt they were only "promoting 
enriched experiences in their classrooms" (Cramer, Coleman, Park, Bell, \& Coles, 2015, p.6).

Pre-service and new art educators are required to take some form of an introduction special education course. The text used in these classes is informative; however the text does not focus on different activities that can be used with students that are not labeled as having an educational or medical disabilities. According to the authors, "the text focuses little on the students with the increased need for accommodations" (p.7). This article focuses on this population of students because sometimes it is difficult for art educators to address these low incidence students need in a large public school classroom setting. When I was working as a Behavioral Health Tech at an urban health center in West Virginia, I would have to accommodate to my clients' needs when we were working with art materials. I would have to alter brushes in order for my clients to grasp the brush and paint. I would also purchase material such as jumbo crayons that my clients could hold unto. I would pay attention to what the clients were interested in, and give them the option to choose what project they wanted to do. The authors of this article also found that art teachers that had a least taught twenty-one students with PVSMD reported high levels of knowledge compared to teachers who taught students with less severe needs (Cramer, Coleman, Park, Bell, \& Coles, 2015, p.17). They also found that teachers who felt most prepared were "the ones that used multiple approaches for accommodations or modifications such as special equipment, peer or adult assistance, modified rubric and quizzes, assistive technology, and assessment based on participation, rather than the finished product" (p.15). This study showed that art teachers felt prepared when dealing with the categories of art knowledge, characteristics of students, 
assessment, and classroom behavior management;, however they felt less prepared with these same categories when it came to student with PVSMD. The authors also felt further preparation in knowledge of enriching experience, assessment, and behavioral management was greatly needed in the art classrooms.

In art as in many disciplines you learn by doing, and perhaps preservice art educators need more opportunities to be immersed into classrooms with a diverse population of students, with a variety of needs. Also I think it would be crucial that the special education and art departments in schools do peer coaching to further enrich students with PVSMD learning experience, and keeping up with IEP, and keeping up to date with current findings and research in education. I also feel that both art education courses and special education courses need more hands-on tutorials and demonstrations for preservice teachers, in order for them to learn how to modify and accommodate art lessons for this population of students.

\subsection{Art Therapy with Autism}

In order to give medical professionals, families, and anyone seeking knowledge about art therapy and the benefits of art therapy for students affected by ASD, the Autism Society of America and the American Art Therapy Association (AATA) formed a partnership and provided a tool-kit. Try to imagine yourself as a person that is over stimulated, cannot focus, has a difficult time communicating, and extreme anxiety. For someone who has ASD, "art therapy is an excellent tool for providing pain relief". Art therapy is also a great visual tool for opening up communication for students that are over stimulated, difficulty focusing, and many forms of anxiety (“Art Therapy \& Autism," 2017). Art therapists are experts in providing visual, sensory rich opportunities for 
individuals with autism (Nichole Martin ATR). Another great advantage for students with ASD is that the art making process can be used to enhance communication, ease stress, pain, and loss; improve cognitive and motor skills (“Art Therapy \& Autism”).

A successful art therapy program forms a unique treatment plan for each patient, allowing them to feel safe, comfortable, and enriched in the creative environment. Art therapist are also very professional when it comes to keeping up with current research and practices in their field ("Art therapy \& autism," 2017). The article gives the reader of list of several options of art therapy programs to look into. These include: hospitals, schools, private practices, and studios (“Art therapy \& autism”). Programs that are still being offered today are: Social Support Group Preliminary Result (0308), this program is an art therapy autism social support group. Social art based lessons and field trips are designed to help clients with Autism and Aspergers. The second program is Art Therapy \& DIR/Floortime Model (0310). This program teaches art therapists to follow the child's natural emotional interests, while also challenging them on their social, emotional, intellectual skills (“Art Therapy \& Autism”).

The article supports how art therapy helps children and children with ASD. According to the article, the "creative process of art making allows for a child to move into the psychosocial stage of industry versus inferiority." During this period, a child with ASD can use the creative process to enhance competency and mastery allowing positive development of their self esteem and relationship skills. Art therapy can allow children with ASD learn fundamental lessons in social skills, and allow them to challenge themselves towards greater mastery of their social, emotional, and intellectual capacities 
and joining others in the creative process. This article also demonstrates how forming partnerships is achievable.

My hope is that more partnerships like this would form within the public school systems. I am also discouraged by the lacking number of art therapists. While I was looking for art therapists to observe during my graduate studies, it was nearly impossible to find one in the state of West Virginia. Hopefully in the future more art therapy undergraduate and graduate programs are offered with licensing in the state of West Virginia. Or at least more partnerships with education and therapy group programs can be offered to help out the students in the public schools.

\subsection{Art Therapy with Depression}

The term depression is a diagnostic term referencing symptoms such as feelings of... "being pushed down, emotional state of sadness, despair, numbness, emptiness, being blue, often lack of energy, focus, pleasure, social interaction, and lack of appetite" (Brooke \& Myer, 2015, p.6). Brooke and Myer use the metaphor of the "black dog" to describe depression. The "black dog" in many cultures and forms of media is considered to be a dark omen, following and lurking behind the person like a shadow (Brooke \& Myer, 2015, p.1). Brooke and Myer illustrate examples of how metaphors give us a new way of looking at things and give us an insight with the 'unconscious' process of associating with image, emotion, memory, and thought (p.4). The authors' book follows 
the link between creativity and depression, giving a history of depression throughout life span, and examples of famous figureheads that used the arts to deal with depression.

In the 1800 s mental illness was known as mania, melancholia, and dementia. By the middle of the 19th century the term lypemania was replaced with depression (Brooke \& Myer, 2015). Experts have always debated whether depression was a form of madness, but today we have a greater understanding of what depression is. Everyone experiences sadness in their lifetime, but that form of sadness is usually short lived. Depression depending on the trigger like losing a job or loved one, may last over a long period of time (Brooke \& Myer, 2015, p. 5).

Depression in children and adolescents differs from depression in adults. Depression in children and adults has been recognized as a risk of lasting morbidity. According to McGlasson, children that had depression are 5\% higher to have depression when they become adults, and a higher rate of impaired social lives, careers, and family connections (McGlasson, 2012). Stressful events such as abuse and neglect often trigger depression in children; these events are also three to four times likely to trigger major depression in their lifetimes (p. 6). Some children express their depression by showing aggression. This aggression may be triggered by the child when encountered with a threat and the "use of proactive and purposeful aggression may be used to achieve a certain reaction or goal" (Brooke \& Myer, 2015, p .6-7).

Adolescents are far more likely to have depression than children: "20 to $40 \%$ of teens will at least have one depression episode in the length of two years" (Brooke \& Myer, 2015, p. 6). Teens are $70 \%$ more likely to have more than two depression episodes before adulthood (Brooke \& Myer, 2015, p. 6). Among teens "untreated depression is the 
number one cause of suicide, and suicide is the third leading cause of death, suffering from depression makes it twelve times more likely to attempt suicide" (p.7). Warning sign of depression may include "talking or writing about suicide or death, not taking care of personal appearance, elevated emotions, giving away personal items, making plans or methods for suicide, saying goodbye in advance" (p. 333). Other risks to look out for are depression and mental illness, physical illness, substance abuse, prior attempts of suicide, family history of suicide, social isolation, homelessness, conflict with family, sexual, physical, and emotional abuse, low self esteem, bullying, and easy access to weapons at the home (p.333).

Further into Brooke's and Myer's book they mention other creative therapies along with art therapy that might aid in treating many forms of depression. These therapies include collages, play therapy, and storytelling through play, music therapy, community music/choir therapy, movement therapy, drama therapy, using masks as a nonverbal storytelling tool, and animal assisted interaction therapy (Brooke \& Myers, 2015). In the last chapter the authors cover the ethical consideration for treating depression through creative approaches. Both are very clear when mentioning that all therapy associations including AATA are bound to follow ethical guidelines when treating all their patients, and following and keeping their clients work and records confidential (Brooke \& Myer, 2015, p. 328). When it comes to the client's work, the therapist must arrange for secure storage of their clients work. If the artwork is an important part of the therapy process, the artwork must be in secure storage for at least seven years (p. 330). Depending on the state, client's artwork can be safely stored till the client is twenty-five years of age. The work does not have to be guarded in a museum 
setting, a simple closet or art closet with lock would be appropriate (p. 330). As an art educator I feel like I should also follow these guidelines when it comes to their confidentiality within their artworks, but given that I am not an art therapist, do I keep their work under lock and key, or do I let them keep the work as a keepsake?

As professionals we are reminded to follow the ethical codes and guidelines, and that we learn from our mistakes, and that communication and awareness is the key to healing (Brooke \& Myer, 2015, p.331). Both authors highly encourage creative therapists to continue their education and keep up with contemporary trends in the field. They warn therapists about burnout, which is also common with educators. They remind the reader that human nature is complex, and that whatever creative therapy you practice you will run into dilemmas. Depression is a very scary subject for educators; you want to see your students happy and thriving in life. I appreciate the warning signs the authors listed in this text for teacher and parents to look out for. Children are very good at hiding their feelings, and they don't always communicate what's wrong. That's why I feel art therapy in the classroom can bridge a gap in communication, that way the teacher can help the student before it's too late. Or at least give the student the tools to help them cope with negative feelings before the worst happens.

\subsection{Art Therapy Importance on Children Mental Health Awareness Day}

Priscilla Frank author of arts and culture for Huffington Post, starts off her article mentioning National Children's Mental Health Awareness Day, a day in May that brings awareness about children, teen, and young adults' mental health and the emotional struggles they face every day. Frank states, "Art classes and art therapy is a growing field and that it's a great combination of both psychotherapy and visual art making” (Frank, 
2015, para.1). Frank also got the opportunity to speak with Dr. Sarah Deaver, President of the American Art Therapy Association. Deaver states, "The biggest advantages is that art can express things that are not expressible verbally" and that "the arts play a huge advantage for people who don't have the language skills to talk about what's inside of them" (Frank, 2015, para.1).

In honor of the 15th anniversary of this day, Frank reached out to art therapists that mainly work with children and teens. One art therapist was Gretchen Miller. Miller started her career at The Cleveland Christian Home as the founder and art therapy coordinator. Now Miller is now a certified trauma consultant through The National Institute for Trauma and Loss in Children (Frank, 2015). Frank asked Miller a series of questions related to the art therapy profession, also covering questions about working with younger children.

Frank: Summarize how would you define art therapy?

Miller: Art Therapy is the psychological use of art media and creative process, given by an art therapist to help foster self-expression, creating coping skills, and strengthen sense of self.

Frank: How did you get involved in this field?

Miller: I have always been involved with the arts. In high school I became interested in mental health and psychotherapy. In college I explored art therapy and was fortunate to get my undergrad and masters in art therapy. Combining my love for the arts and psychology to help people.

Frank: Did you face any challenges when working with children? 
Miller: I mostly worked with foster children; they had emotional and behavioral issues stemming from early childhood. Parents were not able to take care of children, that when my work focused on trauma. Working with children from traumatic backgrounds taught me how to use art to heal wounds.

Frank: What does an art therapy session look like?

Miller: I like using group therapy. It gives the sense that the child is not alone. The main job is finding an art activity that helps with a certain problem.

Frank: What activities have you found to be beneficial?

Miller: I like to focus on interventions that provide safety for the user. I also focus on their reaction and bodies' reaction. For soothing I like projects like painting, drawing, and mask making. For feeling such as fear, anger, sadness, pain, worry, it's easier to use art medians than verbal expression.

Frank: In your opinion, what advantages does art therapy have over other therapies for children?

Miller: Art making comes very naturally to children, and they're open and want to engage in it. Giving art therapy to a child will strengthen them, and give them coping skills when they become teens and adults. Art therapy is more about the process not the product.

Frank: What kind of progress have you seen while working with children?

Miller: I have definitely seen the process come full circle. Feelings such as anger and sadness are not as consuming in later work. A child's sense of self and their ability to cope becomes stronger. Art therapy provides a safe containment for these overwhelming emotions. 
Frank: Can you tell us the importance of Children's Mental Health Day?

Miller: It's helpful to put a spotlight on children's mental health to bring awareness; it also takes away the stigma about mental illness. It gives a sense of hope and early intervention before mental health issues arise (Frank, 2015, para.7).

I appreciate that Miller brought up that art making comes easier for children, and that it gave them the coping skills when they become teen then adults. In the counties surrounding my hometown in West Virginia many elementary schools have no art programs, the students do not have art till they get into middle school. I noticed when I was doing lessons during my student teaching, that many students had trouble communicating complex emotions, or did not want to talk at all. After several projects some of the students slowly started to share and feel a little more comfortable about sharing their artwork. I also appreciate in the interview that Miller brings up that art therapy takes away the stigma of what the public views as therapy. Miller says she "uses group sessions to help the child feel like they're not alone" (Frank, 2015, para. 6). Using art therapy approaches in the public art classroom may take away the stigma of therapy and students would feel more comfortable about talking through their issues through the use of art. Miller works mainly with extreme cause, however I may come across students in my class that are going through trauma. I need to consider with all my students what lessons, emotions, and materials to use to address what is going on at that certain time.

\subsection{Art Therapy for Children of Hurricane Katrina}

Through a workshop in Alabama called "Hurricane Healing", Martha Pitt a writer for the newsletter "SparkAction", goes through the events she witnesses with young children (Pitt, 2006). The children the author observes were re-homed as a result from the 
destruction of Hurricane Katrina. Pitt encounters a young boy that draws a picture of a face, colors it blue, and draws waves under the eyes. This image may represent the sadness this child felt from the flooding and having to leave his home. Pitt encounters another boy that makes an ant out of pipe cleaner and says to the therapist, "the ant is scared of drowning" (Pitt, 2006). After the traumatic event of Hurricane Katrina many children did not know how to cope with the experience they went through. The concept of art therapy offers ways for children and young adults to revisit these traumatic experiences in ways that are healing (Pitt).

Paige Asawa is a therapist and co-author of the book A History of Art Therapy in the United States (1994). Asawa discusses how, "art therapy is uniquely positioned to assist children with trauma" (Pitt, 2006, para.2). Asawa and several of her colleagues assisted in the hurricane healing workshop. Because of the complexity of the disaster, it affected the children in different ways (Pitt). The workshop proved how creative art therapy can be extremely beneficial, allowing the children to express the inexpressible and unlock hidden feelings. For some children retelling a disaster can be re-traumatizing opening up painful memories. Letting the children draw, play with clay, or use of other art materials, can allow the child to remember an event and feel less traumatized (Pitt). These same methods and principles of art therapy were also used in Chicago to help public school students who were struggling through emotional issues and events (Pitt).

The students of West Virginia did not have to go through the trauma like the children from Hurricane Katrina did, however West Virginian students go through trauma everyday both internally and externally. Our students deal with poverty, drugs, violence, and homelessness. Many of these students do not know how to cope with these issues and 
find negative ways with which to cope through those issues. All children deal with trauma differently and in the classroom I would have to assess if the students could handle talking about a certain issue. I believe creating a lesson that is relatable for the whole class and not re-traumatizing would perhaps be the correct instructional strategy. This would reassure me that the students could work and create art in a safe and nurturing environment, giving them the necessary tools to start the healing process and help them deal with these issues if they go through another traumatic event in their lives.

\subsection{Art Therapy in the United States}

For the last twenty years Christine Kerr has traveled around the world teaching family art therapy. She wanted to discover how different ethno-cultures dealt with empathy, understanding, and feelings. Kerr stated, "When a therapist is more able to be more open to new attitudes, this increase awareness provides the structural framework to work fully with clients with diverse ethnic backgrounds different from one's own" (Kerr, 2014, Preface). Kerr was concerned whether family art therapy techniques would translate to other countries and cultures. Throughout her studies, themes of "empathy" or “empathic awareness” emerged (Preface). Kerr says in order to achieve empathetic awareness, the therapist needs to focus on the nine family themes, as well as gender issues, economics, marital relationships, work-family issues, intergenerational issues, and child rearing (Preface).

Each culture views these themes of aging, spirituality, and community differently. Some cultures might have similar viewpoints, but how these themes are experienced is often the key to success or failure within an art therapy approach. Kerr discusses family art therapy sessions in a multitude of countries and my writing focuses on Kerr's 
experience with family art therapy session she conducted in the United States, and see if these methods could translate in a public school art classroom in West Virginia (Kerr, 2014)..

In the United States, verbal and visual metaphors are used in both group and couple counseling (Kerr, 2014). Metaphors or figurative language are "used as an inter play between emotion and logic" (p.8). When using the arts in a group or family session, art can lower defenses and resistance. During the art making process, the family or group can form a partnership as a whole to create a piece of work. During this process visual metaphors would start to appear and the family and the therapist would talk about these metaphors. However, it is very important for the therapist to, "be careful to listen for metaphors in speech as well as visual metaphors, as both are equally important in order to gain access to the client's perception of their world and events" (p. 14). After visual and verbal metaphors are exchanged, this can lead to the therapist to ask questions, allowing the client to form new pathways of thinking. The types of questions that the therapist can utilize are "Deconstruction questions- externalizing the problem, open space questions: uncovering unique outcomes, story development questions- developing a new story from seeds of unique outcome, meaning questions- challenging negative images of self and emphasizing positive outcomes represent preferred experiences" (p.14-15).

I agree with Kerr that there needs to be greater empathy and awareness when dealing with diverse cultures and other beliefs besides your own. The U.S. student population, belief system, and family dynamics are always changing. I found it interesting that American therapy sessions use a lot of metaphors and visual language in order to communicate with each other. In the art classroom I may have to interact with 
students and their families during conferences, but I believe I can design lessons that use symbols, metaphors, and visual language, so that students can show their parents or caretakers what the art really means. This deep discussion between the student, teacher, and caretaker may form a positive partnership while creating a meaningful piece of art.

\subsection{Superheroes and Emotional Intelligence}

Most children in today's society lack the skills to identify their own emotions and the emotions of others. In Hitt and Stewart's book, Superheroes Unmasked an Amazing Approach to Helping Children Learn Social/Emotional Insight and Skill (2009), the authors discuss emotional intelligence to help young children deal with their emotional struggles. "Emotional intelligence is an ability or capacity to perceive, understand, assess, and manage the emotions of one's self, of others, and of oneself within a group: teaching involves ways to identify and describe emotions for young children towards developing emotional intelligence" (Hitt \& Stewart, 2009, p.9). The book was designed to educate the reader about emotional literacy for children in the 2 nd through 6 th grade. During this time we learn about ourselves emotionally, and there is no turning back. This book can be used by students both young and old, educators, parents, councils, and any other person seeking help with emotional health (Hitt \& Stewart). The authors find this troubling because this may lead to increased violent behavior in schools across the country. The authors believe that if students are in tune with their emotions it may result in better overall health and lifestyle. The chapter also touches on brain activity and patterns among children. When a child is under a great deal of stress, anxiety and depression may affect their brain and ultimately their performance in the classroom. Once a child knows how to communicate their emotions through art, play, or other forms of creative therapies "they 
will be able to heal and improve their performance in the classroom" (p. 9). The authors stress the importance of therapists providing a safe and nurturing environment for children to be able to communicate their emotional intelligence (Hitt \& Stewart). The authors also explore why teachers should incorporate "superheroes into their lessons when dealing with emotional intelligences" (Hitt \& Stewart, 2009, p.11). Superheroes have given men hope, dreams, and the faith that good will triumph over evil, this belief dates back to ancient Greece and Rome. In today's society, superheroes are everywhere: in movies, television, and advertising, and these heroes have inspired both young and old to help others and help themselves in time of dire need. These heroes are a good source for people to release their anger, aggression, anxiety, and other emotions. When people lock up these emotions it is like a "ticking time bomb" (p.11).

What are the benefits of using superheroes with small children? The authors explore this phenomenon and state that, "using superheroes allows children to explore ways to settle conflicts in non-threatening ways, act with compassion, and help other in need" (Hitt \& Stewart, 2009, p. 11). Superheroes allow children to use their imaginations to dream of what they can be. This approach can show children how to use powers wisely, understanding the difference between violence and pretend violence (p.11). Children have to use their power over their own emotions in a responsible way. Another appeal to superheroes is that many of them have alter egos, i.e., Bruce Wayne as Batman, Clark Kent as Superman, and Peter Parker as Spider-man. Children often times "can use the vehicle of secret identity in two ways: to block a weakness, or see themselves transforming into a more powerful character" (p.12). 
Superheroes also help children in a scientific and neuropsychological way. Some children in their lifetime have witnessed or been part of a traumatic event such as abandonment, violence, domestic violence, etc (Hitt \& Stewart, 2009, p.12). These traumatic events will change the chemistry of the brain, scientists realized that the brain is very adaptable and will react in a certain way in order to protect itself (Hitt \& Stewart, 2009, p.12). The authors suggest using "superhero play, because this will make the child use their limbic system to control their facial expression, tone of voice, and body language. This gives off a strong visual and emotional effect when covering children trauma" (Hitt \& Stewart, 2009, p.12). Another appeal to using superheroes is the use of visual imagery and strong storytelling (Hitt \& Stewart, 2009, p.13). Storytelling allows a child to explore and express their fears, concerns, and other complex emotions in a safe way (Hitt \& Stewart, 2009, p.13). A child's storytelling and artistic skills vary with age. For example in Piaget Developmental Stages, a child that is around the age of 2 through 7 is in the preoperational stage of thinking. A child in this stage will tell a story with a beginning, middle, and end, and good always triumphs over evil. In Lowenfeld artistic stage, this age group is still in the scribbling/mark making, then into the pre-schematic1st representational stage, and then the schematic stages of making symbols and forms(Hitt \& Stewart, 2009, p.13) As a child gets older their storytelling becomes more complex and their ideas of what makes a villain and superhero changes. Also they also consider peaceful ways that the hero can resolve a problem (Hitt \& Stewart, 2009, p.13) The next section of the book compares the superhero back-story into real situations a child can experience, and also why we need villains. One of my own personal favorite superheroes is Batman. The character Batman witnessed his parents being gunned down, 
and this particular event changed his outlook on life. Batman used his pain and anger and transformed it into something good to help the city of Gotham. He also used symbolism, such as the black bat, which is usually a symbol of fear, and transformed it into a symbol of hope.

We all have a dark side, and that is what a villain is: a dark side to the superhero. The classic super villain motives are usually revenge, power, or just creating chaos. Sometimes we see ourselves as a villain. The conflict between being a hero and being a villain to a child can represent the conflict they are battling internally. We all "personally love to see stories with conflicts similar to our own through the use of fictional characters. When a child sees a superhero win against a villain it gives that child a sense of ease when dealing with their on conflicts" (Hitt \& Stewart, 2009, p.15).

This book provides seventy or so superhero-themed lessons using art and play therapy. I identified those art lessons I felt would be most beneficial in the art classroom using an art therapy approach. Two lessons, which related to each other, stood out. One was "Create your own Superhero"; the other was "Create your own Super-villain." Combining these two lessons to show both a student's light and dark side could be very therapeutic (Hitt \& Stewart, 2009). If both lessons were combined it would be a 90 minute lesson. Using Pop-Art/Roy Lichtenstein as an art history reference, the objective would be to encourage imagination and provide an opportunity for self expression (Hitt \& Stewart). The lesson introduces a history of superheroes and main villains; their powers, weaknesses, and back stories. For materials it would be up to the teacher, but mixed media may produce the most interesting results. One thing I disliked about this lesson is that there was a template of the human form for the students to draw. As a 
preservice art teacher, I feel that drawing and covering how to draw the human form might allow for more creativity. The students would then create the hero and villain names, giving the characters powers, costumes, and a narrative to the story or back story.

Other lessons I felt would be therapeutic was the Spiderman themed lesson called "Catch a Bully in a Web", whereby the student draws a web and glues on words or things that bullies have done to them; or the Captain America themed lesson called "Super Power Reflector Shield", where students create a cardboard shield that slows down and attacks, and gives the student the opportunity to critically think about resolving conflict (Hitt \& Stewart, 2009, p.31). Group superhero themed lessons like "The Justice League", where the students' team up and draw or act out a situation without using words, would also be great teamwork exercises.

Another lesson that could be very symbolic and therapeutic is the "Superhero Helping Hand Mural” (Hitt \& Stewart, 2009, p.59). This lesson was "designed to show students that everyone can be a hero when they work together. Each hand is decorated in their personal style, and on each finger writes how you can help someone. The hands are then joined in a chain and displayed on a mural" (p. 59). I did not like, however, some of the activities because they relied heavily on worksheets, which in fact may take away some of the power of the art making process.

Superheroes are a great medium to use in the art classroom because they are current and the students can relate to a hero or villain in some aspects. Superheroes and comics are also very strong visually and symbolically. The lessons we learn from superheroes gives us tools that may help to cope with daily situations. I could use the 
lessons in this book as a warm up exercise or art lessons with an art making, art history, and art therapy approach within it. 


\section{CHAPTER 3}

\section{A PHENOMENOLOGICAL PAPER}

\subsection{The Phenomenon}

While I did not conduct a research study per se, this paper followed a phenomenological approach throughout. The main question that framed my work within this paper was: could I combine art therapy and art education approaches together? Using art therapy approaches in the West Virginia art classroom I student taught in gave me invaluable insight on how to deal with students' own emotional and psychological issues in their daily lives. One phenomenon that I identified by using this approach was that art educators are not really prepared for dealing with students' emotional and overall well being, or have little training or knowledge of these issues that students may be going through. I noticed that students frequently deal with social problems such as drugs, emotional and physical abuse, bullying, depression, suicide, family disputes, and many other contemporary issues in our society, and that teachers, professionals and caretakers were either unaware of these problems or simply did not know how to deal with them.

While art and art making may already be truly therapeutic, I wanted to do lessons that combined the art therapy approaches I learned through my graduate studies with the West Virginia Department of Education's CSO's and objectives, giving students a variety of new techniques that explored different art media as well as some additional knowledge of formal art history in order to help them work through their personal issues. 
Many traditional and contemporary artists use art as a therapeutic tool to give meaning to their lives. I noticed in my own art journey throughout middle and high school that we never discussed the work we made. The students would make the art, the art would be graded, and then we would move on to the next project. This changed when I went to college. In these classes, after doing a project, we would have art critiques, discussing the methods and meaning of why we made a certain piece of work. My peers and professors would talk about the pros and cons of each piece, and give suggestions and constructive criticism in order to grow as an artist. This process was new for me, and as I learned to discuss my work, I would notice emotional aspects and themes translating into my work, making it easier for me to discuss these emotions within a group. This lived experience led me to want the same for my students at Sites A, B, and C; to be able to discuss their work in a productive and safe environment, and communicate their inner feelings in nonverbal and positive ways.

\subsection{Forming the HTP Test}

When I first designed the HTP lesson I only knew aspects about the test from my own personal experience of taking it when I was a teen seeking therapy, and the information our class read in the art therapy courses. I knew most of the HTP tests were done with drawing tools, so I wondered if adding both drawing and painting, keeping in mind I would have students in mid to upper elementary stages of school, could change the outcome. My first thought was to let the students draw with crayon, then put watercolor paint overtop. This I reconsidered when I realized I did not want to limit my students' options, so I decided they could choose between using crayon, watercolor, or a 
combination of both. Another thing I had to consider was marrying both art therapy and an art lesson together. I had to act like an art teacher, but an undercover art therapist.

\subsection{Forming the Color Therapy Lesson}

As I was forming ideas for lessons for middle school during my student teaching, I knew I wanted to use color, shape, art history, and a new art medium. I asked my cooperating teacher what art media the students had not used or had little experience with. Her response was "soft and oil pastels" (personal communication, February 23, 2017). This was perfect because it gave students an opportunity to experiment with blending and creating new colors, while experiencing a new medium. I knew very little about color therapy, except for the activities I witnessed with counselors doing activities with coloring sheets. Coloring sheets were acceptable, but something about using coloring sheets in an art classroom bothered me personally, as I felt it took away from the art making process. When thinking of artists for reference and inspiration for this particular lesson, Georgia O'Keeffe came to mind. Georgia O'Keeffe used complex themes of life, death, and change throughout her artwork as well as objects like flowers and desert landscapes, but employed abstract colors to express these themes. I noticed how these students liked to draw small and not use the whole paper, and they were obsessed with making the objects in the drawing appear realistic. With this color lesson I wanted to challenge them to use the whole page and use abstract color combinations. As I was forming the power-point presentation I set up interactive activities that would utilize the Smart-board technology I had in the classroom. I felt confident that my students would respond positively to this lesson, all the students had great personalities and wore 
bright colors and accessories to express themselves. I just felt we needed to create art with an abundance of color to spread good vibes in a monotone school hallway.

\subsection{Forming the Action Painting Lesson}

During my student teaching placement at the high school in rural West Virginia, I noticed students' moods changing as students expressed to me how much pressure they were under. Some students would seek the school counselor for advice on how to deal with stress. The cooperating teacher would give the students one day out of the week, (usually a Friday) as a time when they would catch up on work for her class, and work on other major projects for other classes. One day we made stress relief balls using balloons and sand. The students responded positively to the stress balls (even though we had to dispose of them because we learned one of the faculty members had an allergy to latex). Through this process, however, I realized I wanted to do a lesson that dealt with art history and art therapy. While I was at the high school, I helped with the art club. This club was very involved with functions in the school and local community. Each year the students would organize a World Cafe, a fun day for students at the end of the year before finals. Local organizations and fellow teachers would do activities with the kids. The club members asked if I wanted to do an activity. I found this would be the perfect opportunity to do an outside project. At first I thought of a sidewalk chalk lesson, however this project would last temporarily and I wanted the students to take something home with them as a keepsake. Then as I was looking through my art history textbooks, I saw Jackson Pollock's splatter paintings! I realized how this might be the perfect combination of both art history and art therapy. I needed to get prepared with all the materials and 
know the environment where I was going to perform this lesson. I also wanted to make visual aids directing their attention to the works of Jackson Pollock. 


\section{CHAPTER 4}

\section{DATA ANALYSIS}

\subsection{Introduction to Findings}

The purpose of my paper was to implement the use of new art therapy activities and tools into my already existing art lesson plans to teach all students. This chapter reflects on my experiences of observing different age groups of therapy through both individual and group sessions. The places I observed were a government residential facility in rural West Virginia (Site A), a middle school in rural West Virginia (Site B), a high school in rural West Virginia (Site C), and a rehabilitation center in urban West Virginia (Site D). I had the opportunity to observe both rural and urban communities during my observations, and a variety of societal issues. Throughout this process, I observed middle school, high school, teen suicide groups, adulthood groups, and senior citizen therapy at senior living centers. I used observations from the professionals I observed, which revealed the tools and techniques, experts in the field used in each age group as well as document analysis to formulate lesson plans, which employed the three art therapy approaches of color therapy, action painting and House-Tree-Person (HTP) activities.

While my own lived experiences lead me to believe there is a positive relationship between how these approaches can better serve students and what is actually practiced in the classroom, I realized that being able to understand the inner working of the child 
combined with strategies used in the classroom is critical to helping students solve and deal with their own problems.

Judith Rubin observes that art can be used as both an assessment (to check for understanding) or as an effective tool to help with the healing process (Rubin, 2010). Art has been used for healing since the time we as humans could draw on cave walls, but yet in the mental health field art therapy is still relatively young (Rubin, 2010). While I was not granted the opportunity to observe a practicing art therapist during my clinical observations due to the lack of trained professionals within West Virginia, I was able to observe master counselors and social workers who used art within their practices.

\subsection{Site A - HTP}

The HTP lesson was designed for my art therapy class; the class went to Site A on a Saturday in September 2016. For this lesson the teachers brought in a variety of materials, since we were not aware of what materials the facility had and/or the layout of the room. There were helpers for each of the teachers because of the big size of each class. In this lesson, I conducted the HTP test with the youngest group of students. The materials used in this lesson consisted of watercolor paper, watercolor paint, brushes, water and cups, paper napkins, crayons for crayon resist, and handouts of different trees and houses. The Social Studies Standards used in this lesson was People, Places, and Environments. The West Virginia Visual Art CSO used in this lesson, VA.O.3.1.02 use drawing and/or painting media to create artwork., VA.O.3.2.06 explore the concept of composition and space as it relates to foreground, middle ground, and background, and VA.O.3.5.01 identify different reasons for creating art, e.g., aesthetic, historical, functional, and nonfunctional. The skill the students would be learning, was students will 
able to use watercolor and crayon resist to create a house, tree, and person. These elements will show aspects of their personality. The students had the following four objectives for this lesson. One, students will apply watercolor and crayons techniques to create a HTP as an aspect of their personality. Two, students will demonstrate what the Tree, House, and Person represents in their lives. Three, students will be open minded to interpretation of their work, and the work of others. Four, students are welcome to share their work, and open up dialogue with other students.

In this lesson, I had a dozen students in my class, with student age ranging from 18 months to 9 years old. The 18 month old had a parent to assist them and older sister took part in the class. This was problematic as I had designed this lesson for $2^{\text {nd }}$ to $3^{\text {rd }}$ graders. I made a visual PowerPoint and handouts for the students to use to help them form a realistic tree and house. I also performed a demonstration on how to use watercolor materials with crayon resist. The students had an option to use any materials I provided to experiment with.

For the introduction of this lesson I engaged the students by asking if they have ever taken the HTP test before. Next, I presented a PowerPoint presentation that discussed a brief summary of HTP, I did not give the students a lot of detail because I wanted the results to be genuine, so I told them we were going to paint one house, one person, and one tree. I then showed the students an example I made with watercolor pencil (see Figure 1). I asked the students what feelings did they see when they looked at the example. One of the students stated, "The girl looks sad." I asked, "Why do you think she is sad?" she responded. "Because, she is not smiling." Then I asked them what else did they noticed in the picture? One of the students responded, "The grass looks dead, 
maybe that's why she is sad." Then I asked the students, "Who do you think is the girl in the picture?" the students thought about it for awhile and one of them responded, "Is it you? The girl has the same hair color as you." I said yes, this was me at my house in the country. I then proceeded with different meanings of colors, placement of objects in the foreground, middle ground, and background. I also included interactive games of different types of trees, parts of a house, and different types of houses in the presentation. After the presentation, I demonstrated to the students how to use watercolor paint and crayon resist. I also told them to make one house, one person, and one tree.

I went around and assisted students if they needed it. Many of the students enjoyed the watercolor paint and changing the color of the water. The two younger students' ages three and four showed me if you put all the colors together in the water you make black. Student W, male age four put a black puddle in the right corner and dragged the brush in a S shape line (see Figure 2), then did the same with a red puddle. Student A, female age three was having a really rough day. She had a head injury that night and was still in some pain, she started to get irritated and cry. The helpers and I tried to calm her. After she calm down, she seemed to get easily frustrated with the paint, I asked her if she would like to use crayons, markers, or any other materials we had in our supply box. She decided to use the crayons and drawing paper. She started to make soft organic shapes (see Figure 3). When the students were halfway done, two other students joined in, I caught them up on what we were doing, and showed them the same presentation I gave the other students. The helpers were assisting students as I was giving instruction. The two boys were around seven, and said they used watercolor before and 
started immediately. Student B did not start making the house, tree, or person. Instead he started making black birds on his paper (see Figure 4).

After the students were done, it was time to talk about the house, tree, and person they made. The paintings were laid on a table and student W shared first. Student W shared that his family was going to move to a new house, and that there was a muddy river behind his house (see Figure 2). He stated, 'I don't like the river because it's dark and moves fast," he also shared, "I not a good swimmer, and I might drown." In my opinion this shows that student $\mathrm{W}$ is unsure about his new surroundings, and that this new environment of a river setting is scary to him. Student W is four years old, and the objects in his painting are very abstract, however if you notice in Figure 2 that the black lines he made are similar to the motions of a river. Also I noticed when student W was playing with changing the color of the water with the watercolor set and created black, he made the connection of the black water to the river he was moving next to. I asked the class, "What could student W do to not be so uncomfortable around the river?" Some of the responses were, "he should stay with his mommy and daddy if he goes to the river," and "he should wear a life jacket." My response was, "These are all really good ideas, and sometimes experiencing a new place can be scary. Sometimes it takes time to get use to new places." Another student stated, "I like to fish on the river." I stated, "That's right, you can fish, boat, and sometimes swim in the river, however we need to be careful and stay with a parent or wear life jackets when you're near or on the river." Student W seemed reassured by this, and we moved on to the next painting. Student A was the next to share, she said she wanted an ice cream house with a princess flag on top, and she made herself purple because that was her favorite color. Student A had a rough time in 
the beginning; however she showed pride in her work, indicating she is very confident and imaginative three year old girl. The last student to share was Student B, he said, "I wanted to add more than just a person, house, and tree, so I added animals. Animals are really important to me, so I added my dog. Whenever I take him for a walk we always see a lot of birds, so I added them (see Figure 4)." This shows me that Student B is very mindful of his surroundings, and is very detailed.

Overall I believe this lesson was successful, however there were some issues. Not having a sink to change dirty water was a big issue, and going to the other side of the building to get the water cost us a lot of time. The age gap was also challenging, the older students were able to follow the objectives and use the painting materials. The younger students such as the 18 month old needed assistance from the mother, and could not communicate feelings, however the painting activity was a bonding moment for the baby, mother, and older sister. With the baby, the use of big colored blocks to build a house would be more appropriate. I was very pleased some of the students were able to share with the group what they created and the feelings they felt when sharing with the group. If I was going to do this lesson again. I would do this lesson with older students around upper elementary to upper junior high. Another thing I would change is the materials used for this lesson. Perhaps drawing materials such as drawing pencils, charcoal, or maybe pen and ink would be more successful. The greatest part of this lesson was I was able to get more insight about these students and their personalities. Each piece of work was completely different. In the public school system I would like to do this as a progression assessment exercise throughout the year. One at the beginning of the year to 
find out a little about the students, then one in the middle, and then at the end of the school year to see if anything has changed with that student.

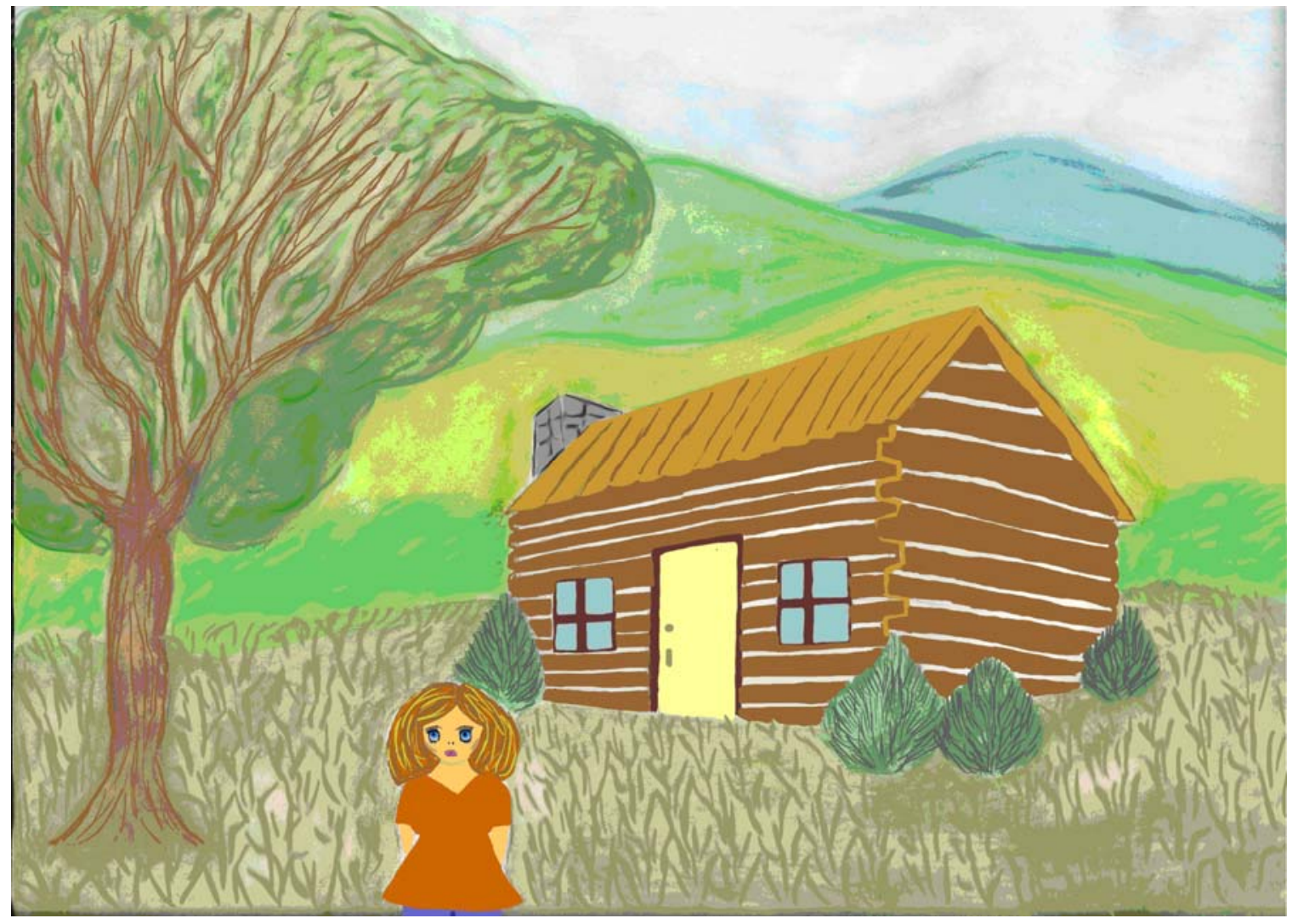

Figure 1 Site A - Teacher Example HTP 


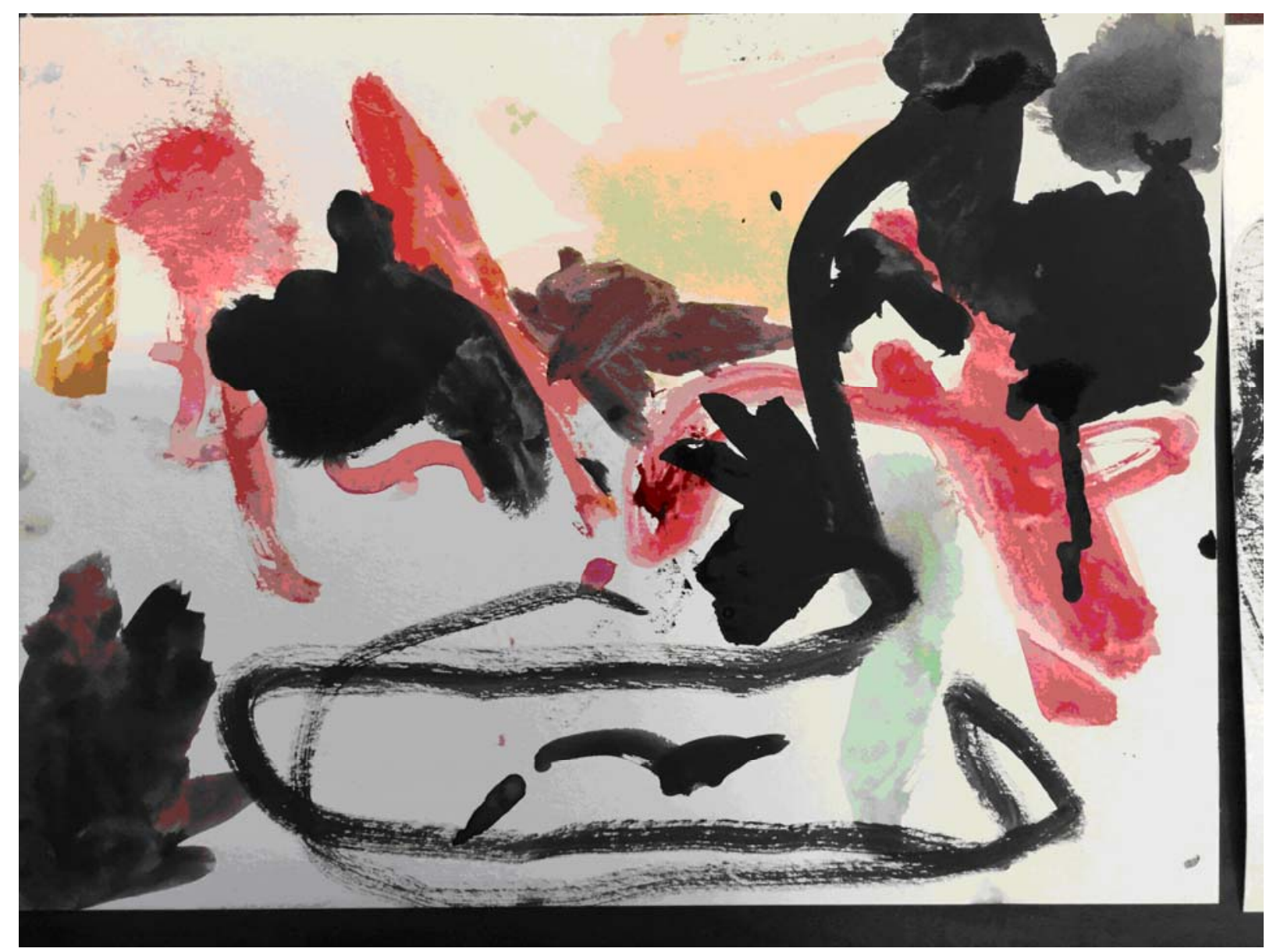

Figure 2 Site A - Student Example of "Black River" 



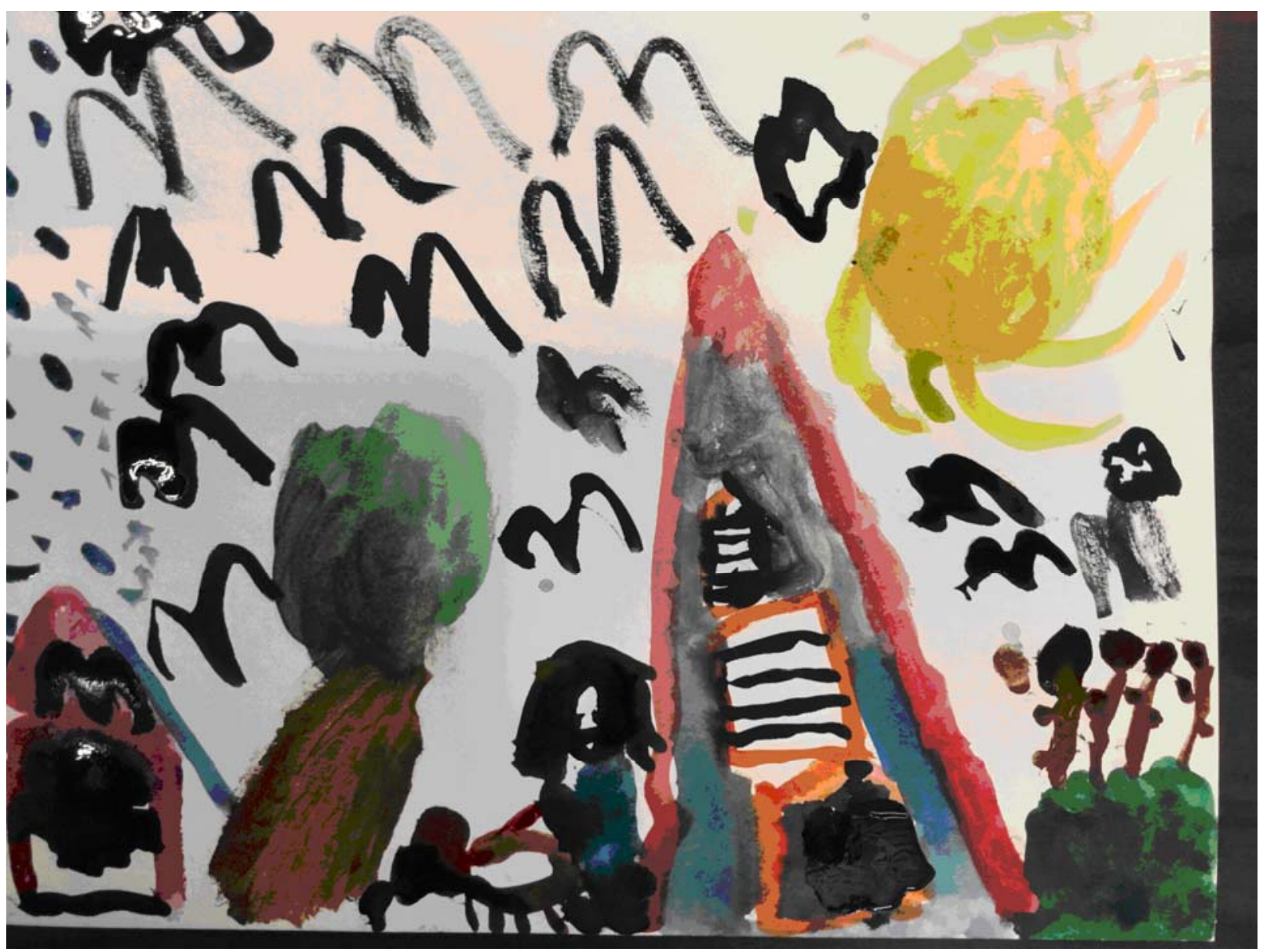

Figure 4 Site A - Student Example of "Swarming Birds" 


\subsection{Site B - Pastel Color Therapy}

The color therapy session took place at Site B at a small rural middle school in West Virginia. I conducted a lesson with the $6^{\text {th }}$ grade class inspired by Georgia O'Keeffe. Georgia O'Keeffe liked to use organic spaces, color, and close up perspective in her work. Figure 5 is an example of an abstract flower using a multitude of colors to inspire the students. O'Keeffe also liked to do themes of death and beauty with animal skulls, so I also brought in animal skulls like deer and boar for students that did not want to do flowers.

For this lesson I wanted the learning focus to be color, space, shape, organic shape, a new medium soft or oil pastel, and the artist Georgia O'Keeffe. The materials used in this lesson were pencils, rough draft paper, eraser, magazines, computers to research images, pastels, pastel paper, and paper-towel square for blending. The theme for this lesson was time, continuity, and change. For the objectives I ask the students to create 3 thumbnail drawings of a flower or skull in the style of Georgia O'Keeffe and get approval by Ms. Elliott before starting project. Students will understand the use of "Space" by making the image enlarged. Students will use a variety of color and will use pastel blending techniques, and use material in a safe and respectful way. Students will replicate a pastel drawing in the style of O'Keeffe by creating an enlarged flower or animal skull.

I started the lesson with a bell-ringer on a PowerPoint presentation on the SmartBoard based on the vocabulary in this lesson. Each bell-ringer came with a game I set up so student could interact with the Smart-Board. For example I had the question "Draw me an example of an organic shape?" with the Smart-Board pen student came up and drew 
an organic shape. Then on the presentation I showed examples of O'Keeffe's work, and told a little bit about her. I then turned the lights on and had the students gather around me to give them a demonstration of how to draw parts of the flower and skull, then how to blend the oil and soft pastels (see Figure 6). I gave the student the option if they wanted to use oil or soft pastel. Majority of the students went with soft pastel. I let the students go on the computer for a limited time to find flower and skull ideas. I also had real skulls and a variety of plant books and magazines that the students could look at. I also told the students that they did not have to use the same colors in the pictures. I like to use humor in my lessons, so I told the students, "instead of free range chicken, you are free range artist, go crazy and create."

Student came up to me to get their thumbnail sketches approved, then I talked to each individual student and asked which sketch they were going to pick for the final project. I then gave them some scrap newsprint paper to practice their blending with the soft pastels. After the student felt comfortable with blending I gave them the pastel paper. Student N came up to me and asked, "can I add something in the background with my rose?" My response was, "yes absolutely, just make sure to enlarge your rose like in O'Keeffe's work." I came back some time later and noticed in Student $\mathrm{N}$ was adding orange, blue, and red behind his rose (see Figure 7). He later asked me, "how can I add rain, should I make the rain blue?" I told him, "let's look at some images on the computer and see what rain looks like in images." We found an action shot of rain and the rain had a white strike illusion. Student $\mathrm{N}$ liked this and wanted to try it. He got some scrap paper and practiced before putting it on his final project. When student $\mathrm{N}$ was done and we were having a class critique he shared with us that, 
“....at night in my neighborhood I see cop car lights all the time. Our next door neighbor is an old lady and she grows roses. I put rain in because when I see the cop lights it makes me sad, and they keep me up" (see Figure 7).

I later found out from the cooperating teacher that Student $\mathrm{N}$ lives in a low income house area, and drug bust happen all the time. I was glad that Student $\mathrm{N}$ was able to share through visual imagery and color what happens in his own environment, and that the crime around him concerns him greatly.

Student H really liked O'Keeffe's bull skull paintings, so he wanted to do a bull skull. Student H asked, "Do I have to make the skull white?" I responded, "No, you can use as many colors as you like. It does not need to be a realistic skull, you can go abstract." Student H seemed really excited and started to experiment with different color combinations. Some time later I noticed he was adding oranges, browns, and yellow lines in the background (see Figure 8). He was extremely pleased with his progress and said, "Do you like my background? It looks like flames doesn't it”! I said, "Yes it does! It looks very hot." Then I noticed Student $\mathrm{H}$ was adding pink to his skull. When the class was done and we were having a class critique he shared, "I made the skull pink because my aunt is battling breast cancer, she fights so hard every day. That is why the pink skull is fighting the flames" (see Figure 8). I later found out from the cooperating teacher that Student $\mathrm{H}$ is really close to his aunt, his dad passed away several years ago and his aunt helped out around the house and formed a close friendship with Student H, like a second mom figure in his life. Student $\mathrm{H}$ is the type of student that does not let you know something is wrong and always has a smile on his face. I was glad that Student $\mathrm{H}$ used 
the color pink in association with a cause he is really passionate about. Also Student $\mathrm{H}$ made the connection with the theme of life and death just like Georgia O'Keeffe work.

Student $\mathbf{J}$ on the first day of the lesson seemed very excited about making flowers. On the second day of the project she seemed very disconnected and didn't want to participate. On the first day she picked out a brightly colored daisy she found online, but the second day she came up to me and asked in a monotone voice, "Do I have to use these colors"? I told her no that she had the freedom to use any color she liked, and she went back and sat all by herself. I went to the cooperating teacher and asked if she knew anything about Student J change in behavior. The teacher replied, "No! A lot of her other teachers are worried about her, she is acting the same way in their classes." I went and glanced to see how she was doing on the project, she was only using two colors, egg-shell white and pale peach (see Figure 9). I knew something was wrong, Student J on other projects used bright and vibrant colors. I went over and asked, "Would you like to add some other colors for shading"? She softly said no and asked, "Ms. Elliott do you have a boyfriend"? I thought this was an odd question and said no. She replied, "My dad has a new girlfriend, and I might have a half brother" "Mom is thinking about getting a divorce." This made sense with her sudden mood change and lack of wanted to take part in the lesson. Student J's world just changed completely overnight. We talked for a little while and I told her, if you need anyone to talk to, you have the art teacher, counselor, and me." She seemed to get worried and said, "Are you going to tell them"? I replied, "Nope, it's up to you when you want to talk about it, but when you are ready we are always here to lend a ear." I then gave a nonverbal showing of locking my lips with a key 
and throwing away the key, then a pinkie promise. She gave a little giggle and said thanks, then went back to work.

This project with color really opened up my eyes; it gave me a glance of what they are dealing with on a daily basis. Showing color to represent what's going on in their environment, what battles their families are going through, and showing lack of color when they are uncertain what was going to happen next. If I was going to do this project again I would use oil pastel instead of soft pastel, the dust did make it difficult for clean up time. Overall I was pleased with the results of their work and impressed with some of the feelings the students shared with me during the class critique. 


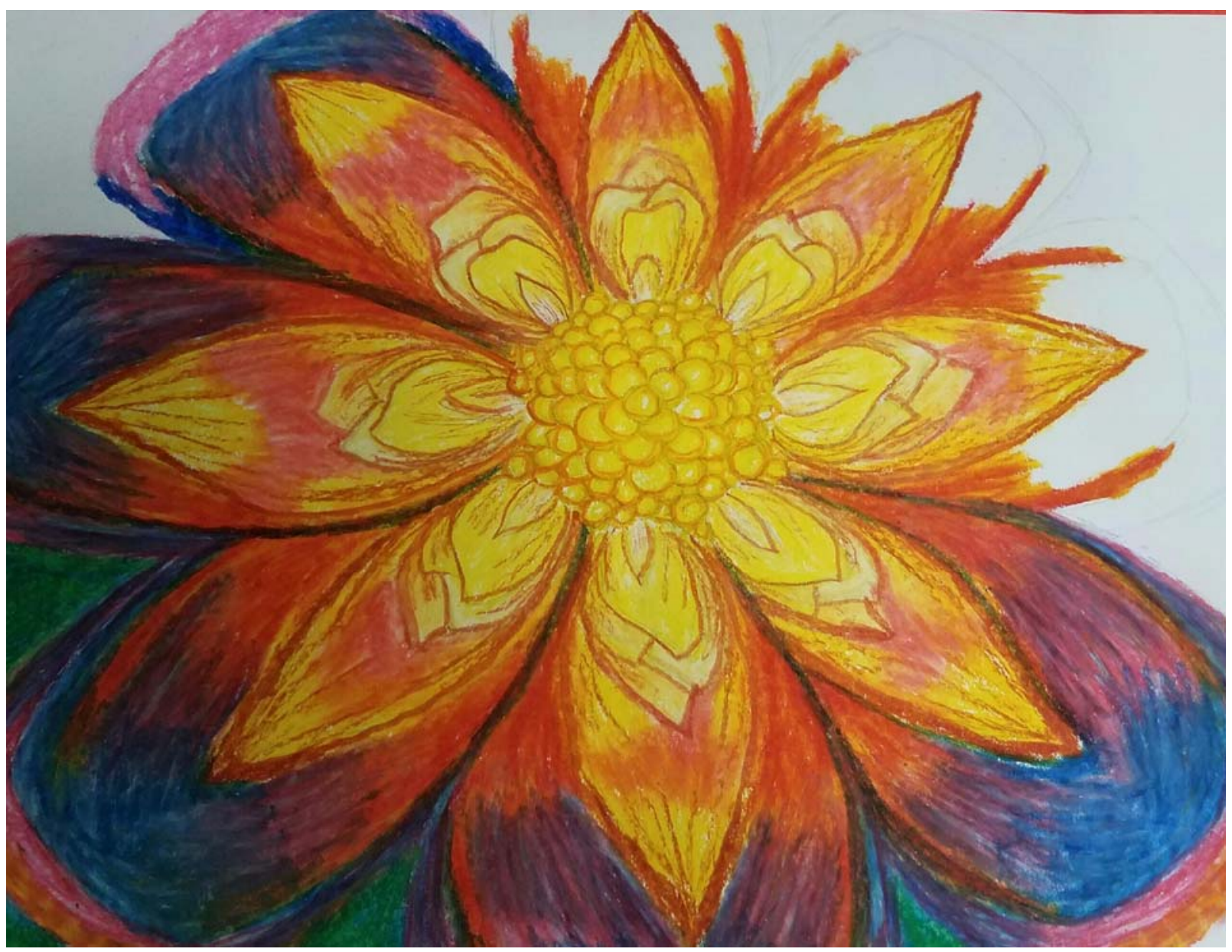

Figure 5 Site B - Teacher Example Georgia O'Keeffe Color Therapy 


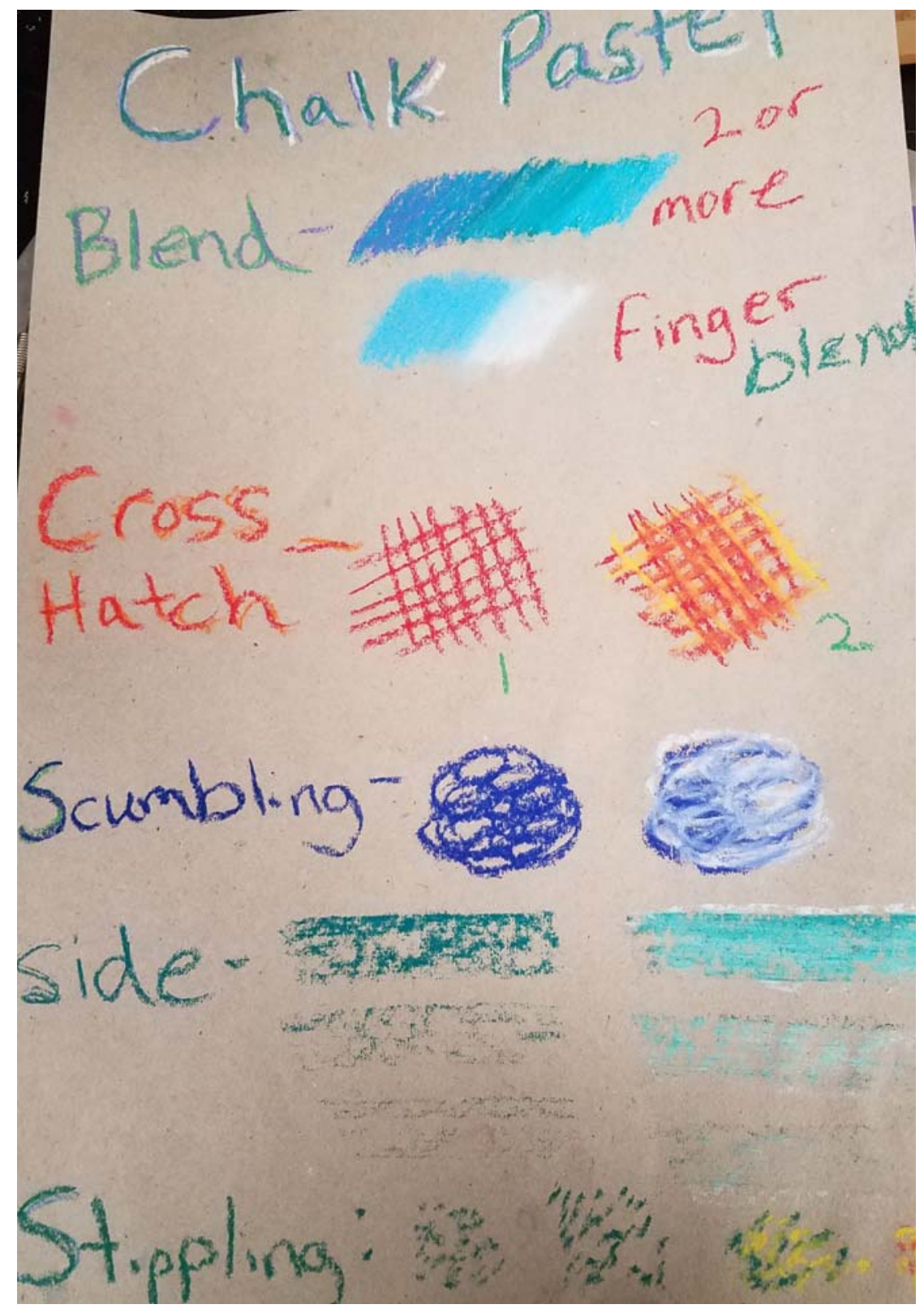

Figure 6 Site B - Blending Technique Example

68 


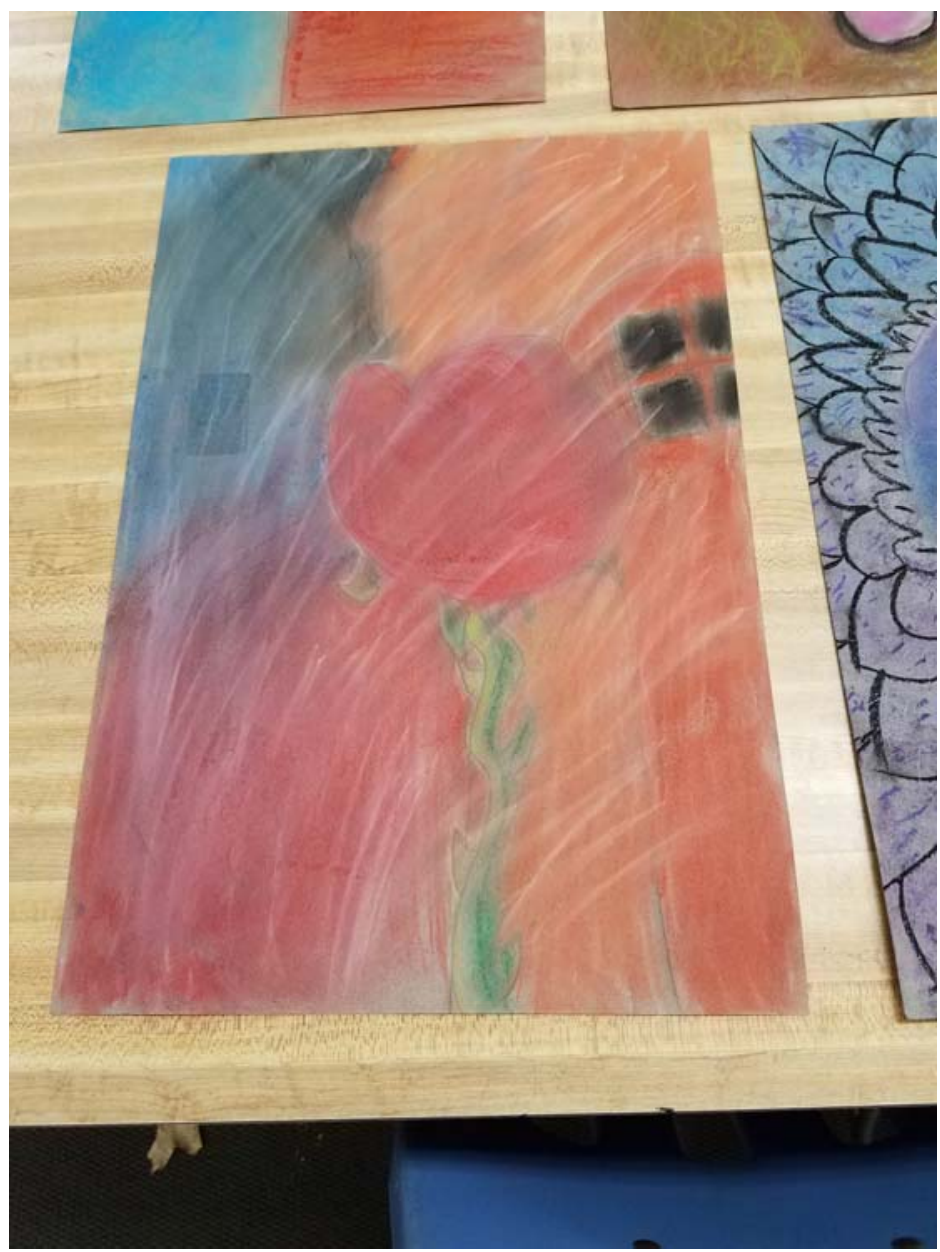

Figure 7 Site B - Student Example "Rose with Cop Car Lights" 


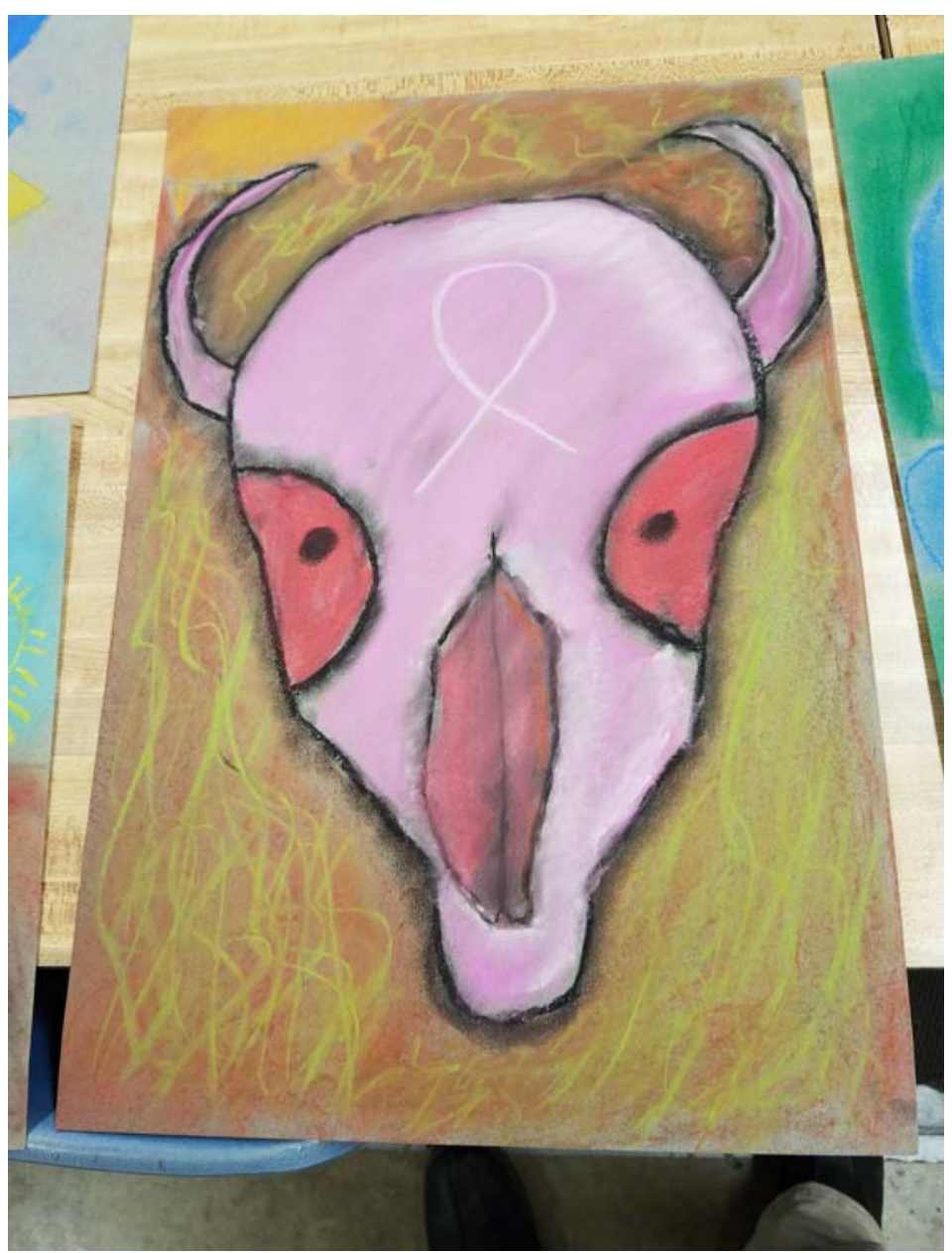

Figure 8 Site B- Student Example "Breast Cancer Bull Skull" 


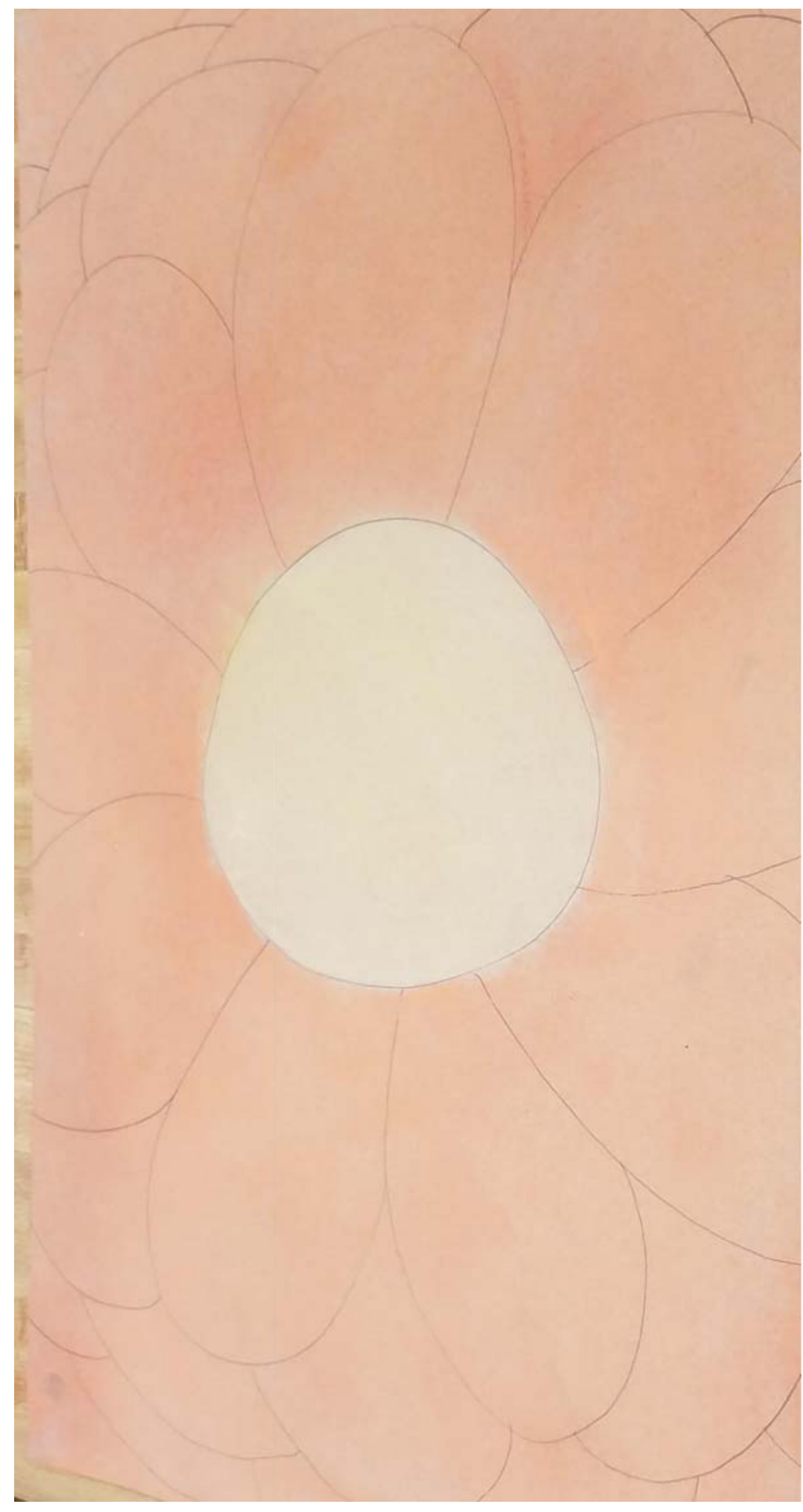

Figure 9 Site B -Student Example "Lack of Color" 


\subsection{Site C - World Cafe Action Painting}

The action painting lesson took place at Site $\mathrm{C}$ in a rural high school in West Virginia. The art club at the school designed a World Cafe day for students to relax before finals. The art club went around and asked local businesses and teachers to do activities with the students. There were activities such as dog training, military obstacle course, makeup design, mask making based on the Pixar movie Inside Out, Native American speakers to talk about and perform ceremonial dancing, henna hand tattoos, and my activity action splatter painting, and many more. I thought this would be a perfect lesson to do outside since it was in late April, and a great art therapy project to help the students relieve stress before finals.

Students signed up during their homeroom classes by grade level. Seniors got first pick of classes then, juniors, sophomores, and lastly freshmen. The day was divided into six classes, and twenty (maybe thirty max, if some of the classes were cancelled) students in each class. All six of the classes were completely filled. Before World Cafe I got donations of semi-used latex house paint, and made sure none of my students were allergic to latex. I also made sure several days before World Cafe that the principle announced on the intercom that students in my class need to wear old clothes and shoes. I also got aprons just in case. I also made a display board with a picture of Jackson Pollock and some examples of his work on transportable display boards I could easily move outside (see Figure 10).

Other materials I used for this lesson were large plastic tarps to cover the grass (not damage the lawn outside of the art room), water buckets, scrub brushes, soap, working 
water hose (to make sure we could clean up any paint that got on students or on the school sidewalk). I also bought spray on sunscreen and got a cooler of cold bottled water for students. I wanted to make sure students did not get dehydrated and protect themselves from skin damage since it was going to be sunny and in the upper 80 s. I also had heavy painting paper sheets for each student, and large scale colored paper banners for group drip painting, ten buckets of house paint consisting of a variety of colors, rulers and unused chopsticks to drip the paint unto canvas, hammer, paint can opener, and I told students they could bring in their on shirts or other articles of clothing to drip paint on.

I started off each class talking about Jackson Pollock and Abstract Expressionism. I told the students during this time, painters were tired of painting realistic things and wanted to experiment what they could do with the paint. I did a demonstration of how you could combine physical movement with painting. I had the students stand back and gave them a scenario. I told the students I was a senior in high school and I worked really hard on a history paper. I got my grade back and I got a low C, and I am so mad I could burst out in fury. I then got a good amount of red paint on my ruler and used my whole body with quick furious movements to apply paint splatters while yelling, "WHY DID YOU GIVE ME A C"! The students thought this was hilarious, but I told them, "you can combine a feeling with a paint stroke using your body." I then asked them to look at my painting and asked "what feeling do you see"? One student replied, "It looks like blood splatter everywhere". Then the students started to talk about murder movies, violence, and anger. I was glad they were feeling these emotions while looking at the painting. I gave them another example; I started to apply gently, soft, controlled lines onto the paper. I ask the students, "What feeling do you see here"? Some of the students 
replied, "Sad, lonely, and bored". Excellent, the students were getting the point, I said, "Yes! This is what we are going to do today, you are going to feel an emotion and translate that emotion using controlled lines with your body movement. Jackson Pollock did the same using abstract lines and splatters using controlled movements.

Students started to get sheets of painting paper and started to apply paint with the ruler and chopsticks. The student that made Figure 12(see Figure 12) said she didn't want to show an emotion, but she wanted to control each line she put on the paper. As you see in Figure 12 she uses both thick and thin lines throughout the painting. Also this student took time to carefully plan out where each line and splatter was placed. In Figure 11(see Figure 11) the student made splatters and then started to use the ruler and drag it in the paint. She asked if she could do this, I said "Yes"! She told me this was a symbolic of her being dragged in different directions. A lot of the students throughout the day experimented with what they could do with the paint. In Figure 13(see Figure 13) in the front left corner, the student held up the paper and let the paint drip down. Some of the other students made objects with drip painting, like the American flag in Figure 13. Another student folded his paper with wet paint and created a symmetrical abstract image. I was very pleased with the results, and the survey of the class said that the students especially enjoyed this class. We did run into some problem with mess and wind blowing paintings. For this project to be successful in future I highly recommend extreme controlled environment, and perhaps a less permanent media such as tempera paint, because it might be friendlier for younger students. 

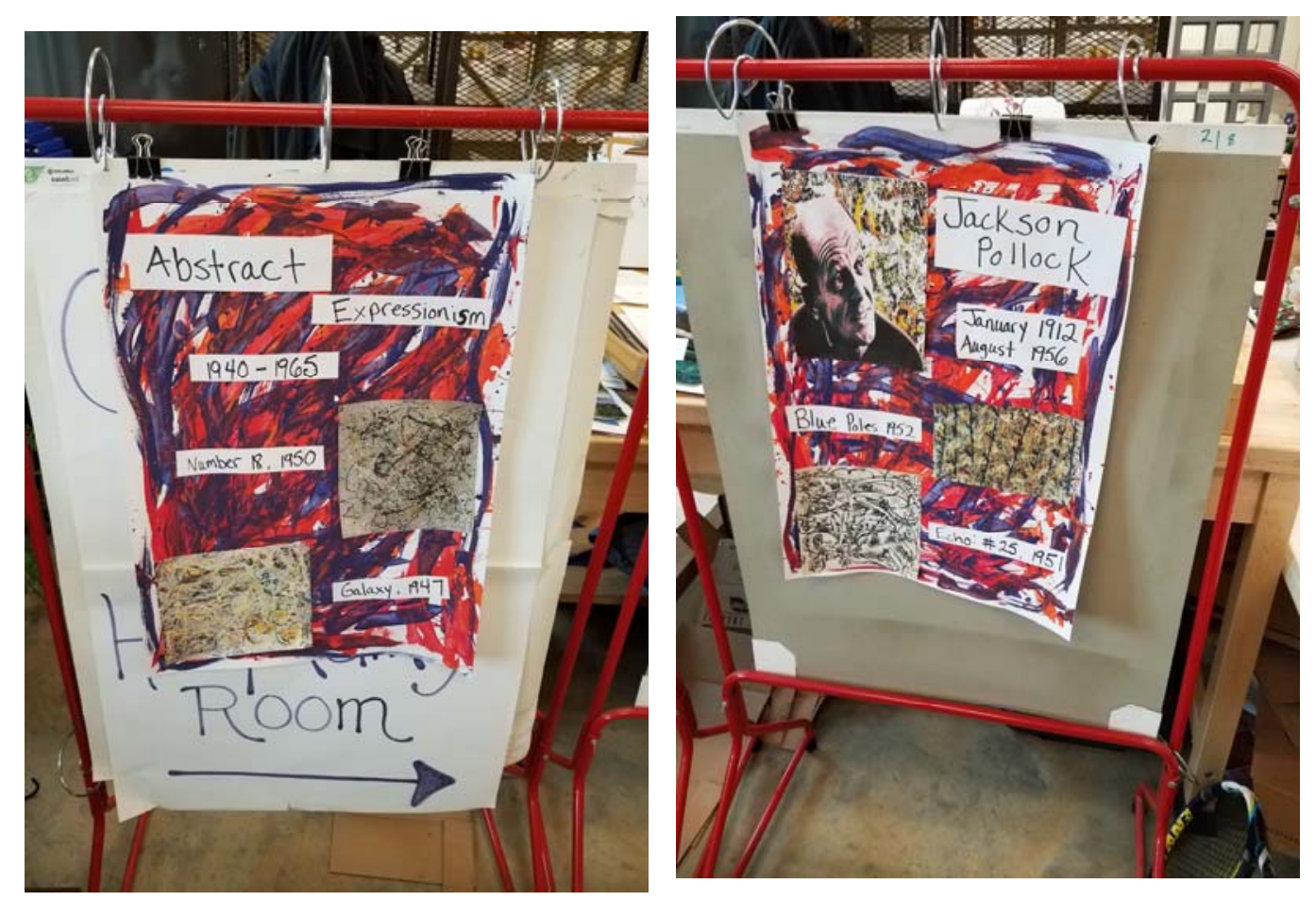

Figure 10 Site C - Action Painting Teacher Display Board 


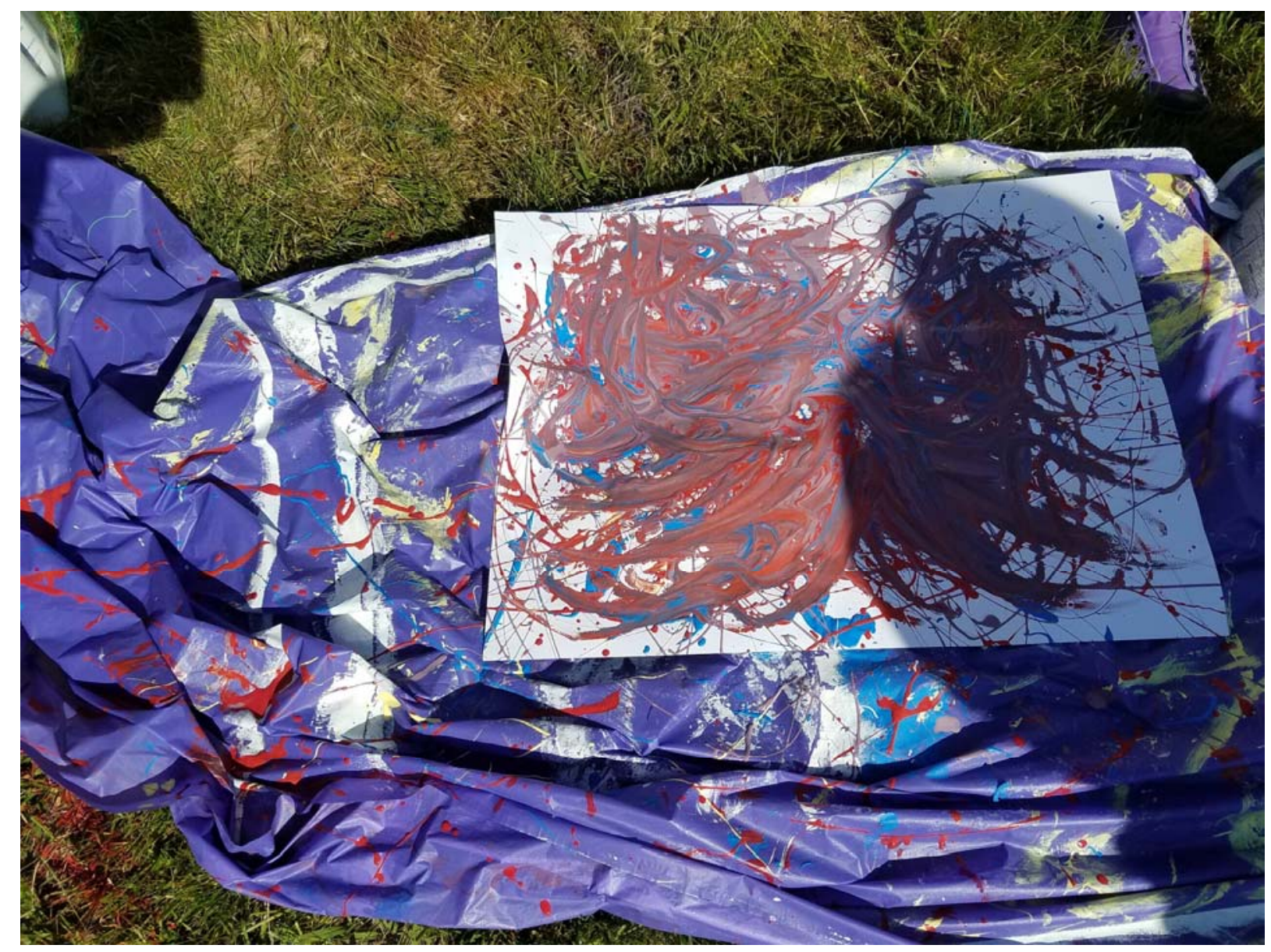

Figure 11 Site C - Student Experiments Blending with Drips 


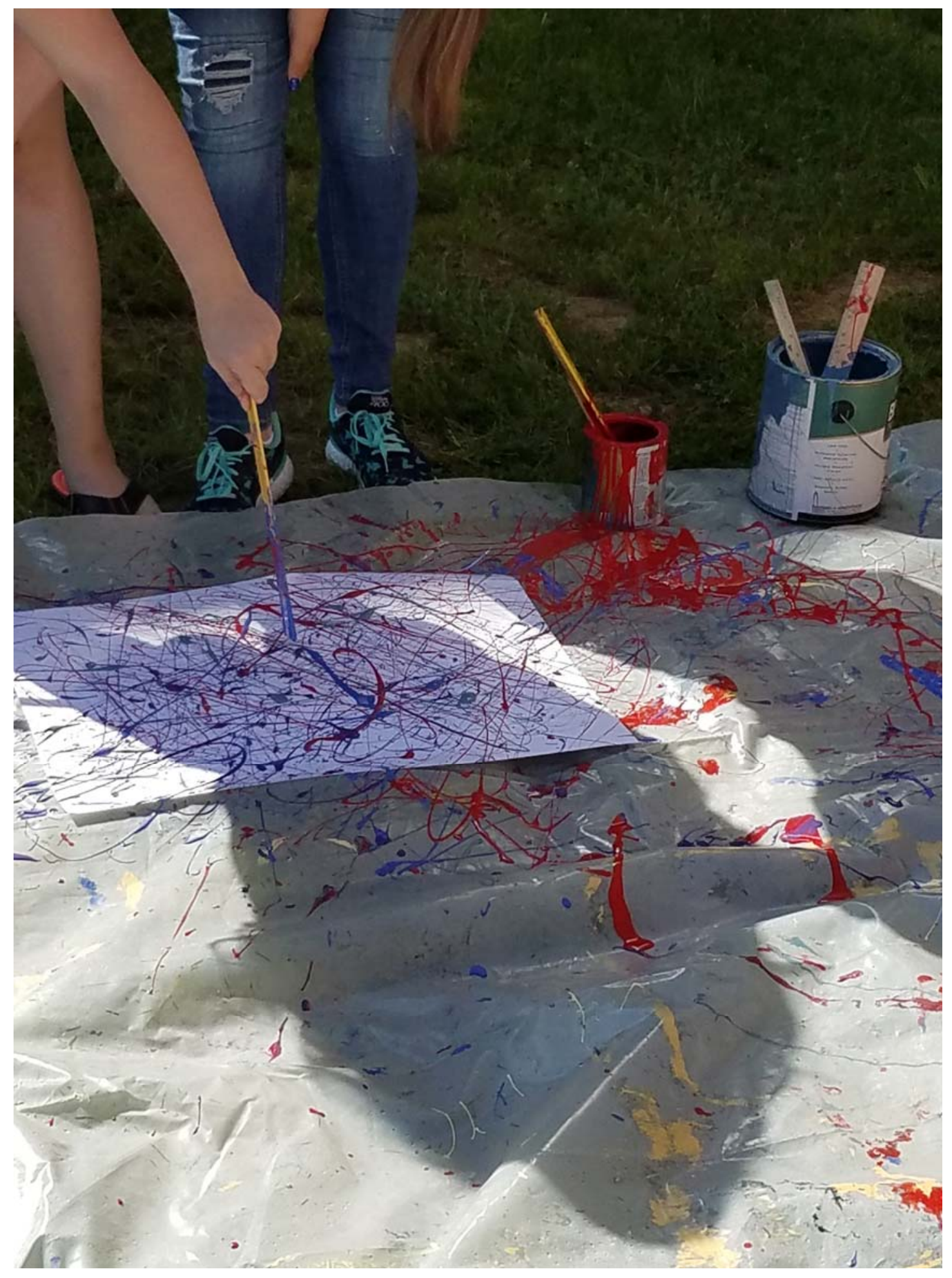

Figure 12 Site C - Student Experiments with Controlled Movements 


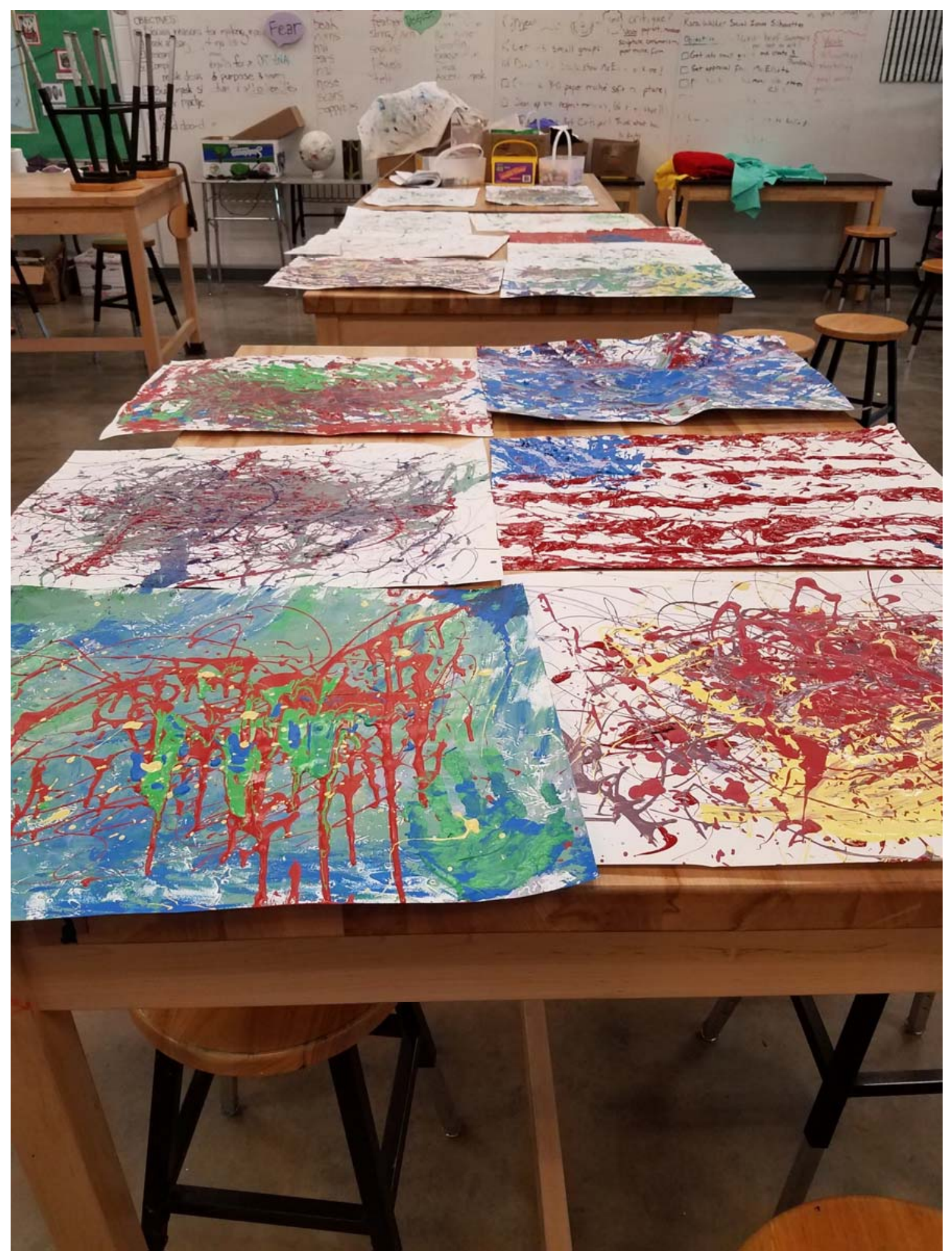

Figure 13 Site C - Students Work Drying 


\subsection{Site B - Girl Power Lunch Session}

At Site B, I started my observation at a Middle School in early February. The school counselor has a Masters in counseling and likes to use group and community therapy. She recently wrote a grant to get students involved with the local senior center. This counselor does a "girl lunch groups" several times a month, and also does play therapy session with special needs students in one of the middle school classrooms. She is well known in the community for her hard work and dedication to the students in the county. During my time at this site, I observed her dealing with individual students, group sessions, and helping students and faculty dealing to cope with the passing of a former student.

My first encounter with this counselor was while I was doing my student teaching at the middle school. The cooperating teacher had a close relationship with the counselor; both women look out for the well being of their students. The counselor is in her 50's and has a very calm and has a relaxing demeanor. Her room was painted country apple red, and smelled like cinnamon. She had quote stickers with words of encouragement; the room had a warm and secure feel to it. The counselor gave me a list of dates when she was going to have group sessions I could observe. She was very helpful and wanted me to observe whenever I could!

While the counselor was seeing other students, I observed with the girl lunch group. There were four girls present at the lunch meeting; I will call them students $A, B$, $C$, and $D$. The counselor was running a little late, she has been dealing with a lot of students that week due to the passing of a former student. She also tended to the students 
and staff members dealing with the student passing. This student passed away from sudden heart failure from natural causes.

While she was seeing other students I observed the girls while they were eating. For lunch they had bean burritos with cheese, pineapple chunks, milk, salad, and salsa. This was an all girls' meeting, and all of them were in the $6^{\text {th }}$ grade. We talked about food, and they recommended local restaurants around the area I should try. All the girls seemed positive, happy, and carefree. The group had a very energetic vibe, joking and eating with each other.

All the girls seem to get along and have a trusting relationship. Students $B$ and $C$ have been friends since elementary school. The girls discussed what they wanted to do this summer, like running a bake sale. Student $A$ has dreams of being a business woman and being her own boss. Student $A$ was very detailed and organized. Mrs. Carpenter came in; one of the girls did not feel like attending today. The girls that were there thought of girls that might want to join the lunch meetings. The counselor said she lost two members because they moved to other schools.

The counselor opened up the discussion; she mentioned that next meeting she was going to do the topic of "Ties that Bind Us" a girl power activity. Then the counselor asked the girl "Is it easier to be a guy or a girl?" The girls were half and half. Students' $D$ and $B$ brought up the male model for the Covergirl commercial. Student $A$ brought up it is harder being a girl because of menstrual cycles. Student $A$ shared a story about her last doctor visit, and that she is worried because she is overweight and that body image is hard for girls. Student $A$ is trying to eat healthier, instead of using diet pills to lose weight. 
Then the discussion went into girl body image verses boy body image. All the girls agreed it's easier to be a boy when it comes to body image. Student $B$ told a joke about body image to try to lighten the mood. Student $C$ then got off topic and started talking about the band One Direction. Then student $A$ talked about her favorite movie stars. Then student $D$ asked "If you were a member of Suicide Squad who would you be"? All the girls responded at once and replied, Harley Quinn! The counselor got the girls back on topic; she wanted the girls to start "Daily Thoughts". The girls were asked to write positive thoughts about themselves and their bodies. Write them on a Post- It note and put it in their lockers to remind themselves how powerful and beautiful they really are. Later they will write positive things about each other.

Student $B$ shared her message, it's a song quote "You are beautiful no matter what they say," and Student $B$ also wanted to share that she is getting better with her ADHD and is not taking as many medications as she use to! Girls then got their lunch trays and went to class. The counselor said that it is typical for these girls to get off topic very easily. I asked the counselor if she incorporates art into the girl group session. She said she would like to, the only art she used was finger painting with pudding with the seniors at the senior center. The counselor stated, "It was a disaster". I mentioned to her that enlarged crayons or other art materials might be more successful than pudding. One project I thought that might be appropriate with these girls with this age groups is have a cutout of a doll with 2 blank sides, have one side represent what the perfect body is, and the other is what they view as themselves. Then once the doll is put together they can attach the words of encouragement on the side of the doll, or they can alter doll. 


\subsection{Site B - Play Therapy with Special Education Class}

Another observation I did was during a play therapy session with one of the special education classes. This took place during $8^{\text {th }}$ period in the special education classroom for children with low-incidence (developmental) disabilities. The counselor had a group of volunteers, typically developing general education students known as STAR students. These students interacted with the students in the special education class. For this interaction the counselor brought in a wide selection of toys and games for ages three and up. There were four students with disabilities with four STAR students, one on one interaction. The counselor, two aides, and one teacher were present to oversee the interaction.

A group of three boys built a marble run system, one typically developing peer and two students with disabilities. Student D, a female student with MID (mild intellectual disability), played "Go Fish" with another female volunteer. The cards were enlarged and had numbers and pictures of animals on them. This is the first time student D played the game "Go Fish", and she followed directions, and understood the rules of the game very quickly. One student with moderate developmental disabilities was wearing headphones; this was done because he gets over stimulated with too many noises. He played with one of the STAR students with a Batman Lego set. The faculty members were sitting at the table with the girls playing "Go Fish" and boys playing with Batman Lego set. The teacher was sitting at her desk completing lesson plans and getting up to see how the play therapy session was going.

The room was very large and a beige color, with superhero stickers pasted all over the wall. The room had a sink, play area, and desks. There was also a beanbag chair near 
books and magazines. The energy of the room was very harmonious; all the groups were communicating and playing well with each other. The counselor mentioned that this play therapy session gives the special education students more interaction with their typically developing peers. The typically developing students do interact with the students with disabilities throughout the day, but this class was smaller by twenty or so students, and more relaxed. I agreed with the counselor, I had special education students in my 7th grade art class; with around thirty students' total. The overcrowding in the classroom can sometimes make it stressful for these students, especially if they are overly stimulated. The special education students had an aide with them, but I didn't have enough time to meet all their needs with overseeing the other students as well. I would like to mix play therapy and art therapy activities together in the art education classroom. This would be a great interaction with the special education students and their typically developing peers, I could modify the lessons in a way that meets all of their needs. This way I could have small controlled groups and tend to them individually.

The counselor has STAR students and special needs students do a play therapy session once a week. According to the APT" Association for Play Therapy states, "Play therapy is a fun, enjoyable activity that elevates our spirits and brightens our outlook on life. It expands self-expression, self-knowledge, self-actualization and self-efficacy. Play relieves feelings of stress and boredom, connects us to people in a positive way, stimulates creative thinking and exploration, regulates our emotions, and boosts our ego. In addition, play allows us to practice skills and roles needed for survival. Learning and development are best fostered through play" (APT, 2016). Sometimes certain students in this class have a behavior issue, if a student's routine is disrupted, luckily all the teachers 
know each student's IEP and are trained what to do if this does happen. The teachers are also brought up to date when a student's IEP is changed. If I wanted to do an art therapy session with these special needs students I would check their IEP, and ask that special needs teacher what materials they would be able comfortable using, that way I wouldn't disrupt their routine to cause a negative behavior. In my special education classes I took during my graduate studies, the main theme of those classes was "know your students". With all my students including the special needs, it is my job to know everything about them in order to modify my lessons to fit their needs.

\subsection{Site B - Student Interaction with Senior Patients}

The last observation I did with the counselor at Site B was with the STAR students doing a visit with the Alzheimer's clients at the Senior Living Center. The students would interact with the clients to help them with memory. Many of the students were interested in nursing or medicine, and stated they liked going to The Senior Center because this would be good practice when they got into the medical field. The counselor has been doing this program for about a year; she got a grant to get materials for the clients and students to use. Materials included enlarged picture books, young children games like Jenga, stuffed animals, and other tactile objects.

The Senior Center was very clean and spacious; the walls were soft pastel colors with paintings throughout the building. The common area was set up like a living room with tables and couches, with large windows with a view of the garden and woods outside. The patients that the students interacted with were all female, it was a small group, around eight patients. There were only two patients in wheelchairs. There were one to two students per client. Many of the clients talked to the students about school, and 
many of the clients talked and joked with the students. One of the patients was not interacting with the students, I heard one of the nurses mention she was not feeling well and didn't feel like interacting with the group. This same patient was holding a doll and was playing with the doll's hair.

The counselor mentioned that she tried doing a finger paint session using pudding but, it ended up being a disaster. The patients and students got extremely messy. The counselor and I talked about getting large newsprint paper and using large crayons and drawing materials, this might be more successful than the pudding project. One project that was mention in the art therapy meetings was the memory boxes; I believe this would be a great project for these patients dealing with Alzheimer's. Also this might be a great group or family session; the family can make the box together and give the box to the patient as a keepsake to remember certain memories or people when they are having trouble remembering.

The hardest part observing the counselor at Site B was one of the past students passed away from heart failure. The teachers, students, and whole community were hit hard by this tragedy. The counselor went around and sought to the needs of all the teachers and students that were having a hard time dealing with that student's passing. The softball team came into the art room and made cards and posters to remember her. They displayed these posters at the funeral viewing. Both the counselor and art teacher had heart to heart talks with students, and continued to ask if the students needed anything to help them cope. The yearbook class had a very hard time and broke down when they went to the funeral. The art teacher and counselor talked to the class and 
talked about happy memories about this particular student, and had deep discussion about the meaning of life and death.

Overall my experience at Site B was enlightening! I was able to learn to multitask, think on my feet, and adapt to all the students needs. As a student teacher in the art department I dealt with a variety of behavioral and mental issues. The most important thing I learnt was to get to know my students and try to meet all those students' needs with art lessons I am teaching. In the future I will try to find lessons that are both educational and therapeutic.

\subsection{Site D - Observation}

The next location I observed at was at Site D in urban West Virginia during the first weekend in March. This location was set up and felt like a hospital. The whole building was quiet and had a clean sterile smell to it. The patients' rooms were small with a hospital bed in the middle of the rooms. There were decor stickers of trees or quotes of encouragement, no art or personal things on the walls. I was able to observe several wings, the GERI unit, Adult unit, and the Teen Suicide Wing. I was able to observe one on one sessions, group sessions, and family sessions.

The person I observed with at Site D was a Licensed Graduate Social Worker. She only works on the weekends doing ten hour shifts. She oversees the teen suicide wing, adult wing, and the Geri unit. The social worker is in her mid 30s and wore semi professional comfortable outfits; she wore her hair down and had a calm personality. Her office was extremely small with a small desk and no windows. The social worker took me to the computer database to look at client's notes while she was getting her data entered into the system. 
I look over some of the patients notes that the social worker was going to have session with that day. The database had medical records with notes from the doctors before they were admitted to Site D. While I was reading the notes one of the patients was giving the staff a difficult time. The staff was very professional and worked as a team to calm him down and assist him back to his room. Other patients in the adult wing were in the lobby watching movies or in their private room sleeping. All of the doors in the building had no handles; the social worker said this was because door handles could be used as a way to commit suicide.

I continue reading the notes of certain patients the social worker told me to read before we went in for one on one session. Patient TB is in the Geri unit, he is elderly man and displayed inappropriate behavior with other female patients and female nurses at the senior living center he was located at. TB had a history of alcoholism and was admitted to the nursing home when he continued to walk into traffic. Another patient was EB, the social worker is working with her on coping skills. She isolates herself from others and only whispers. She does not trust anyone and is extremely paranoid, the social worker advised me not to take notes while we are doing a one on one session with her.

The social worker and I went to the Geriatrics unit to meet with patients TB and EB. The social worker went to the nurses and asked how both of the patients were doing. The nurses replied that both patients were somewhat sleepy, and recovering from illnesses. A virus was going around and the elderly are usually the first to get sick. TB was a tiny man, very thin and frail. The social worker asked him how he was doing and introduced me and why I was there. TB talked about his family and how he was feeling. She used a very pleasant voice, and used calm and open body language while talking with 
TB. The room was small and colored a light brown. There was only one decoration, a sticker decal that said "Live every moment, Laugh everyday, Love beyond words." There was one window of a view outside, a small twin hospital bed, and a bathroom. The social worker and I went to EB room to do an individual session with her. She did not feel like speaking, and stayed in bed, she seemed uninterested with me or the social worker. EB gave us no eye contact, but did answer the social workers question, and stated she would try to come to group meeting during lunch on Sunday. The social worker said she would keep checking on her later in the day.

Next the social worker and I went to do one on one session in the adult wing. The first patient is R; R was19 years old, and has hallucinations and seizures He was watching SpongeBob Squarepants and was drawing on a sketchpad. R told the social worker that he was doing fine and he was not having any negative thoughts. $\mathrm{R}$ wanted to call his friend M. M was a former patients and became friends with R. M is very manic and likes to amp others up. The social worker and M's mother agree to limit the two having phone calls and visits, because they will not improve each other's treatment. Even the staff is not comfortable with the two together. $\mathrm{M}$ was discharged a while back, and $\mathrm{R}$ is getting close to being discharged. $\mathrm{R}$ was admitted in early winter, and he is no longer hearing as many internal stimuli, and did not act on the impulses. He used to swallow objects that were not edible, acting on things he heard in his head. The social worker asked if he was still seeing any hallucinations. $\mathrm{R}$ mentioned that it had been a while--the last thing was a dinosaur in his room about a month ago. R continued drawing and didn't display eye contact while he was talking to the social worker. R shared some of his drawings with me; he is extremely talented. 
The social worker got paperwork for two new clients that would be admitted today, both were teens being admitted for attempted suicide. While she was updating her notes she let me see some of the teens notes from the suicide wing. In this paper I will call the patients B and M. Patient B has MDD, ADHD, and ODD, a friend of hers was successful at committing suicide. B tried to overdose on over the counter medication. With her first session she had mixed feeling about trying to take her own life, stated her throat hurt, and may try to do herself harm again by cutting. Patient $\mathrm{M}$ is diagnosed with $\mathrm{AVH}$ and is having hallucinations and has complaints of lack of sleep, guilt, poor energy, self harm by cutting, and impulsivity. M has had a very hard time at school, and does not relate to family.

The Teen Suicide Wing was painted bright blue and the nurse desk had snacks and personal belongings the teen had brought with them from home, such as personal bathroom items. There is a cabinet full of games and other activities. Most of the patients were sitting in the living area on sofas playing on the XBox 360 playing Minecraft. The social worker and I headed to a private room to have an individual session with Patient B.

The social worker started the conversation by introducing me then discussed the video game the teen were playing. Patient B is tall and thin; she has short cropped hair with long bangs dyed in a variety of colors. She also has big glasses; it appears she is trying to express herself by making alterations to her appearance. She is a 7th grade student enrolled at a rural West Virginia middle school. As the social worker and B continued talking, B gets very emotional. She states how she was sad over her friend's death and her own attempt at suicide. She is showing signs of remorse; the social worker listens intently and seems to be able to relate to her narrative. 
Patient B states that she had therapy sessions in the past, but did not feel comfortable talking to the therapist. The social worker asked what B's early childhood was like. B response was, "False innocence;" the social worker asked her to elaborate. B explains she was raised by a single mom, and that her father left when she was five. Her father leaving had a significant negative impact on her. B states that depression and anxiety run in her family. B is now worried about her grades and things going on at school, and that she doesn't like people in general. The social worker went through a questionnaire of drug use and history. By the end of the questionnaire B seems bored and did not want to talk anymore.

The next one-on-one session is with a patient called $\mathrm{M}$. Patient $\mathrm{M}$ is female, medium height, thin frame, and has long dark hair that she keeps in her face. She is a junior high student at a school in urban West Virginia. The social worker introduces me, and then talks about the Minecraft game she was playing with Patient B and the other teen patients. The social worker fills out the questionnaire form, the same one the social worker used with Patient B. The social worker asks M how she is doing, and why she is there. M seems distant and talks very softly. During the questionnaire M mentions she likes anime cartoons and likes to draw. During the session I was thinking about how the art classroom could be a safe area for her to retreat to if she was having a hard day at school. M mentions she hates school and has anxiety attacks even when just \{thinking about school\}.

After M's session there was a lunch break despite having only 10 minutes to eat a quick bite; the social worker goes off to conduct an adolescent group then a family session with M's family. The adolescent group was small; patients B and M, as well as a 
male patient named D. All three of the teens did a group narrative inquiry exercise called 'fill in the blank" stories. The whole point of the exercise was the characters of the story are related to their situations in life, and how to cope with those situations. The patients seem to have fun, and they came up with interesting responses. As I watch and listen, I realize how this would be an interesting game in the art classroom with using images and filling in the blanks with emotions about the artwork.

Next was the family session with M's family. Her mother, father, and older brother were present, and seemed very concerned for M. The social workers introduce me and explain why I am taking part in the family session; they seem ok with my presence in the room. The social worker discussed with the family options of home school and/or other educational options for M. M likes her art class, and the family discussed meeting with school staff as using the art room as her safe place. When the social worker leaves to get $\mathrm{M}$ to join the family session, M's mother is curious about me; I try to be friendly and professional and inform her I am interested in art therapy because I want to bring it into the art classroom.

$\mathrm{M}$ comes in with the social worker, and she is embraced by her family and starts crying saying she wants to go home. The social worker tells M about the discussion of setting up safe places for her at her school; $\mathrm{M}$ becomes nervous and hysterical and begs her family "not to make her go back to that school." M's mother mentioned with all of them working it might be impossible for $M$ to be home schooled, but finally M's mother agrees that she would be home schooled if that would make M feel safer. The social worker gets them off the topic of school, because it is obviously distressing M. She mentions activities the family could do together to build communication, such as having a 
secret pass code on how $\mathrm{M}$ is feeling on any given day. $\mathrm{M}$ would say she was feeling a level one if she was ok, and level ten would be extremely bad. The social worker would see if $M$ could be discharged that day and go back home with her family.

At the end of a nine hour day, the social worker and I were both exhausted. We both discussed about the observations that happened that day and art therapy activities. The social worker also used art therapy with her patients; saying what a wonderful tool it is for patients that are not so eager to communicate. She told me she was going to do a coloring therapy session with the adult wing on Sunday. Overall my experience at Site D on day one was enlightening, but exhausting.

On the second day of observing at Site D, the social worker and I see individuals; patients in the adult wing, a group activity with the Geriatric group during their lunch, family visitors, group activity with the teens, and a coloring session with the adults. The first thing the social worker has me do is overlook the patients we were seeing on the database. She was finishing up gathering up material for the Geri group and the coloring session. Another social worker with a master's degree takes over the teen group session, and allows me to observe this session. We head to the adult wing and meet with Patient $\mathrm{J}$.

Patient $\mathrm{J}$ is an adult male in his mid 50 s. Patient $\mathrm{J}$ is a very large man; he was admitted by his wife for mania and suicide watch. $\mathrm{J}$ is wearing a back brace and complains about back pain. $\mathrm{J}$ has a history of being sexually abused as a child, and a history of drug and alcohol abuse. In his records it shows how he acts impulsively and aggressively toward others. When the social worker and I went into the room, J seems very irritated. He was lying on his bed with his arm on his forehead. The social worker introduces me, but he seemed very uninterested in me. She asks how he was feeling and 
he said his back was "giving him problems." The social worker continues talking with him. At one point $\mathrm{J}$ had enough and raised his voice and asks why she was asking him these questions when he was laying in bed in pain. J continued to raise his voice in anger. I started to get nervous, but the social worker responded in a calm voice and did not play into his aggressive behavior. She tells J she would come back and check in on him later. The social worker explained to me when a client gets that upset the best thing to do is to give the patient some room. That day was also family visitation day, R's family came for a short visit, but not for long; there were no other visitors in the adult unit that day.

The next session was the Geri group during lunch. Patients were the same two clients from the previous day. The male client has been inappropriate with staff at the nursing home, and the female client attempted suicide and is extremely paranoid. I am told by the therapist not to take notes while in the lunch session because she might feel uncomfortable with my note taking. During the session the clients eat lunch and play memory games to go along with the talk therapy session. Clients are asked to share something from early childhood, high school age, and adulthood. The male client mentions he played basketball in high school. The female client mentions she was once a really good accountant. I was asked to take part in the session and was asked, "What was one thing I did really good in high school"? I mentioned that I was in theatre in high school. The social worker mentioned that with older clients they focus on memory, I wonder if painting a memory box, or making a collage using memory would be a suitable art therapy technique for older clients.

The next session was with the teen suicide wing. The other social worker does a Jenga exercise game using the blocks. Instead of taking away blocks the teens are asked 
to share something and add blocks. I also take part in the session. Students would share their stories and then add a block without making the stack fall down. Some of the teens refused to share at first, but realized later this was fun and started to slowly interact with the group. I noticed how this is a great play therapy technique; in the art classroom I could do a 3-D sculpture lesson by adding or taking away from the art and adding a therapeutic element to it.

The last session at Site D, I was able to see art therapy in practice. The patients were given a coloring sheet of a four leaf clover because it was close to St. Patrick's Day. The patients were asked to write a positive thing in each leaf of the clover, then color the leaf based on the emotion of the word (see Figure 14). All of the patients in this session were male adults, with a variety of emotional issues. Patient $\mathrm{J}$ has a history of violent behavior, he made a rainbow clover and the words were positive things about his wife. Patient $\mathrm{J}$ was very calm and relaxed while he was coloring, but when he was asked to share he left to go back to his room. This is a sign of improvement compared from this morning, he didn't show negative behavior, and just left. I liked this coloring session, it was a nice combination of both word association and coloring. I can see this being used in the art classroom; maybe each person decorates a leaf or petal with a word and putting them all together.

At the end of my observation at Site D, I gained a greater understanding of all the work social workers have to deal with. The social worker I observed was able to do so much in just two days. Both the social worker and I had a brief discussion about the weekend events, and she answered some more questions I had. Aspects I liked about Site D was the social workers and nurses, they put so much time and work into each session. 
The only thing I didn't like about Site D was the setting; it felt too cold and sterile like a hospital. It needed to be warmer and inviting. Hopefully these observations of approaches counselors and social workers use with their clients can translate into an art room setting. Hopefully school counselors and art teachers can get together and do projects with students that help with emotional and behavioral issues as well go with objectives in the art curriculum.

\subsection{Site C - Counselor Observations}

At Site $\mathrm{C}$ in rural high school in the state of West Virginia, there are two school counselors. Both counselors have a master's degree in counseling. Counselor A formally worked at a rehabilitation health facility before becoming a school counselor. Counselor B was a counselor at a female prison. Counselors A and B use a good cop and tough cop approach. Counselor B deals with the 9th and 10th graders and uses a sterner, but friendly approach, Counselor A uses a more gentle approach with the 11th and 12th graders. Both of the counselors do a variety of jobs. Both help with counseling, class scheduling, college advising, and also community activities.

I observed with Counselor A in her office, she is a small and fit woman in her mid 30s. Her room was decorated in a country theme with school medals and her children artwork on the walls. Counselor A always keeps her door open unless she is meeting with an individual student. She is extremely friendly and students joke with her, they feel very comfortable with her. She also helps with getting contact information for colleges or getting letters of recommendations for students. The first day I observed with her, she was getting grades together for senior students that were at risk of not graduating. She contacts the parents by letter, phone call, and email. She said that usually it's only about 
three or four students that are at risk every year. Her advice to me was that as an art teacher you will be wearing many hats. You will be a parent, friend, and counselor to most of my students; because for most of the students they have nothing to support them once they leave the school doors. I was glad and amused that the middle school cooperating art teacher I student taught under, and the high school counselor have the same views! Counselor A said that counselors and teachers have a high burnout rate, and that sometimes that you need a poker face, but take care of yourself so I don't burn out. One time Counselor A got extremely emotional and she talked to me and a special needs teacher in order to get herself calm down so she could continue her work.

Counselor B is in her mid 50s, and is an extreme dog lover. Her room is decorated in dogs and Disney characters. She has a very warm and friendly personality. The first time I observed with her she was with a student that was having trouble focusing and was sent down to her office for sleeping in class. During the last few periods of the day, this student was brought down because she was sleeping in class. This student is known to do this frequently. Counselor B likes to use the tough love approach. She told the student the words she needed to hear, the student started getting emotional and stated she "has given up on school and life". Counselor B is looking at options for this student to go to a technical center right next to the high school. This female student is very talented at construction and welding, I made the comment she was like "Rosie the Riveter". She had no idea who this person was; Counselor B and I told her about the women building planes and tanks during World War 2. The student seemed to be inspired and calmed down. Counselor B thinks that all school should have the options to make alternative education programs for all students if traditional education is not the right learning style. 
The rest of my observation time at the high school with Counselor A and B was a mixture of individual sessions, group activities, and observing them doing school work in their office? I observed students discussing stress about school, prom, relationship, friendships, and future plans. I noticed a personality change when it came to the high school students. The 9 th and 10 th graders made situation seem more dramatic than it needed to be, and they were not sure of themselves. When it came to the 11 th and 12 th graders they seemed very sure of themselves and knew their strengths and weaknesses. Counselor A used to do a project with students using masks. Students would decorate their outside personality and inside personality on the front and back sides of the mask. This might be interesting with a high schools art lesson. One side of the mask as their 910th grade self, other side 11th-12th grade self. Counselor B also does art projects during school activities, for example during World Cafe at the high school, she made masks inspired by the Disney movie Inside Out.

I was so grateful to observe the many processes and situations the counselors and the social workers deal with everyday, both in the medical field and school system. I wish I could have observed an art therapist, but many of the people I observed used the arts as a tool for a variety of clients. I noticed that the councilors and the social workers did art projects that they knew their clients could do. It's just like our education classes and basing the lessons on the student's strengths, "just knowing your students". As I was student teaching I noticed that a lot of the students drew in sketch pad, and would share with me what they drew. As a preservice art teacher I would like to tie in art objectives and therapeutic elements so all my students can benefit in the power of art therapy. 


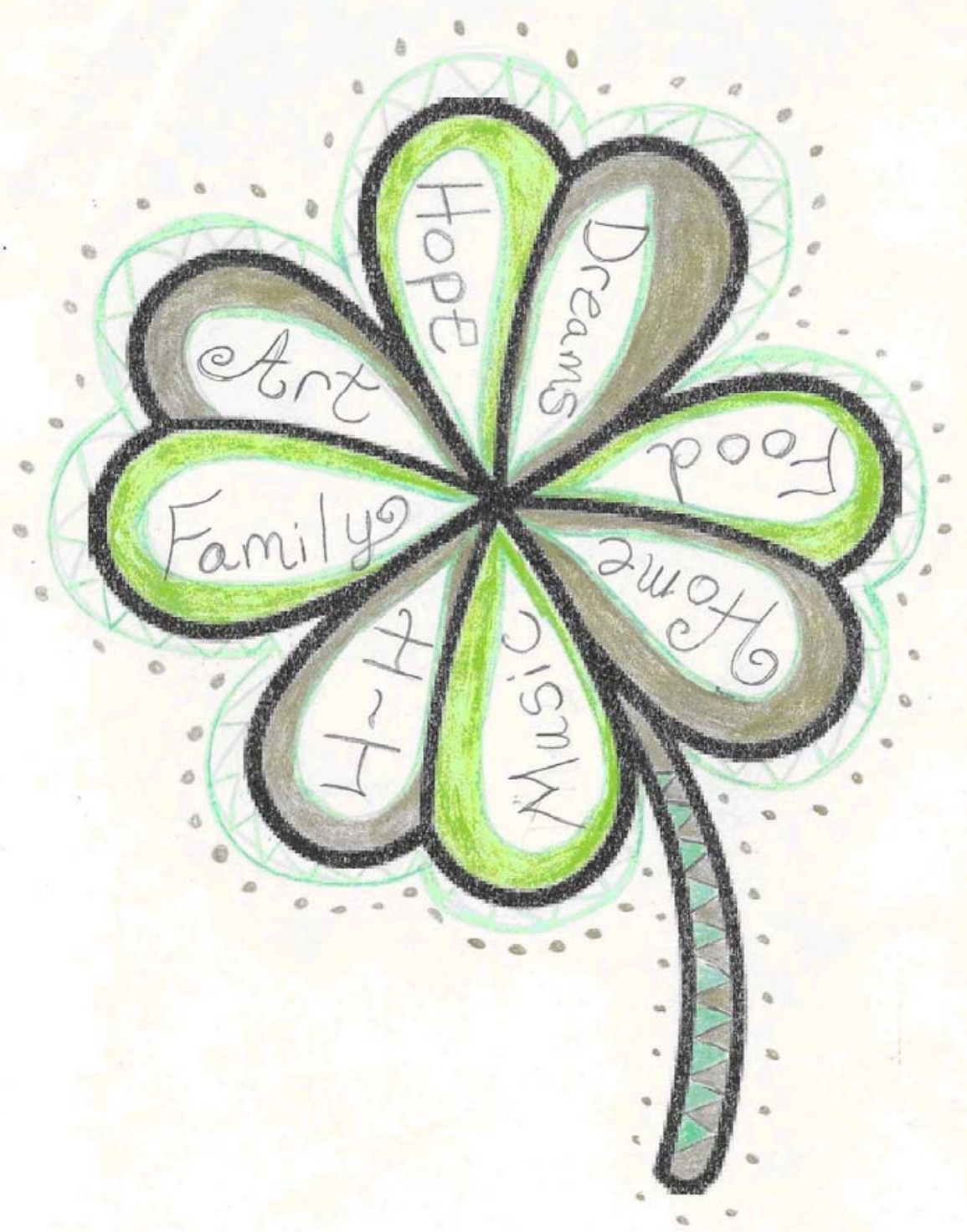

Figure 14 Site D - Coloring Activity 


\section{CHAPTER 5: DISCUSSION AND FINDINGS}

\subsection{Opening}

The purpose of this paper was to discuss how art therapy approaches can be utilized into a regular art lesson plan. This chapter summarizes my personal interpretation of my observations and provides suggestions and changes for more successful lessons, and further research into lessons using art therapy approaches. From my observations and the information I gathered from the literature review, art therapy traditionally takes place in private practices or in controlled group sessions given by a trained art therapist, counselor, or social worker. Art educators are trained artists, with some backgrounds or some training in psychology and special education, but clearly lack the knowledge and skills to tackle the needs of all students, especially those coming from special populations and/or dealing with emotional, social and psychological trauma. During my student teaching, the cooperating teachers wanted to take the art therapy classes I was taking. Both the high school and middle school art teachers have taught for over twenty years, and they felt that the problems the students are dealing with now is the worst they have ever seen. Both teachers as well as myself felt the students overall emotional needs were not being met, and the middle school teacher wished that there were more art therapy opportunities for art teachers and counselors, because it would be beneficial for the students especially in the state of West Virginia.

\subsection{Summary of the Findings}

The literature I collected was useful for art therapy practices, applications, and dealing with a wide selection of population in both private sessions and controlled group session, however it did not deal with art therapy practices in a public art classroom 
setting. Art teachers are very resourceful when coming up with lessons that meet the West Virginia CSO's, and conducting these lessons with a limited budget, however many of these lessons do not deal with what the students need emotionally. Therefore there needs to be a balance of educational and psychological benefits when it comes to art lessons.

\subsection{Reflections on Site A - HTP Lesson}

When it came to the HTP lesson at Site A, I felt it was somewhat successful. I was surprised by the wonderful response when students experimented with watercolor paint for the first time. I was pleased by the work and the students' responses when we shared at the end of the lesson. I felt as the teacher I was able to do a lesson on how to draw a structure of a tree, person, and house, without ruining the result of the test. I felt I was well prepared, had appropriate visual examples, and used technology to my fullest advantage, provided handouts, and was well organized. I also thought I was able to demonstrate how to do watercolor and crayon resist techniques. I also thought I communicated the objectives very clearly without given away the purpose of the test. One element of the lesson I wish that was different is the population of the students in my group. When I designed this lesson it was intended for students around 1st through 3rd grade. I was not expecting students as young as 18 months old. The 18 month child's test was not valid due to his mother doing the project with him, however it was a bonding moment with the mother and child, and the child getting kinesthetic and visual stimulation, resulting as a positive conditioning when it comes to art making. Also the lack of control over the environment was also challenging. The lack of a sink to refill water was a problem, however with the help of aids we were able to proceed with the 
lesson. As an upcoming art educator I will face these dilemmas with any lesson I

conduct, all I can do is make notes and learn from my mistakes, that way when I execute this lesson again it will run more smoothly.

\subsection{Suggestions for HTP Lesson}

If I were going to do this lesson again, I would definitely not use watercolor paint as a medium. Perhaps I would if it was a prism color watercolor pencil, then the students could apply water later. I feel that the results would have been more successful if I would have used a drawing medium's such as graphite, charcoal, chalk, or pen and ink. Also this lesson I felt would have been more appropriate as a warm up exercise then a full length lesson. The literature from Frankish states that this assessment is meant to be quick, because you want the drawings to reflect what is in the patient's subconscious and unconscious mind (Frankish, 2015). I can see this being a progressive art project in my class. Start out the students with the HTP exercise in the beginning of the year, then one midway through the year, and finally at the end of the year. Resulting and finding out if the student grew both in art skills and growth as a person. As for grading this project, I see myself using this as an extra credit opportunity, if they keep all the drawings and turn them in at the end of the year for extra points, then returning them to the students as keepsakes. If I was going to grade this project I would grade on if they created a house, tree, and person to the best of their ability, and for upper level students maybe grade if they utilized foreground, middle ground, and background, shading and maybe adding texture. For an art history reference I could use the piece "Christina's World" by Andrew Wyeth. I truly believe that this lesson would be a great communication tool for the students and art teacher. 


\subsection{Reflection on Color Pastel Lesson - Site B}

Overall, I felt the color therapy lesson using soft pastels was a success. By using art elements such as color, form, shape, as well as the historical reference to Georgia O'Keeffe, I felt this was a perfect blend of art therapy into my art lesson in the classroom. Students enjoyed experimenting with blending techniques, and as you can see in Figure 15 some of the students liked putting the colored pastels on themselves. I was thrilled by the creativity, I was also impressed with the students when they started to experiment with different color combinations. I also noticed the emotions the students were expressing like in Figure 7(see Figure 7). The students work in Figure 7 shows a combination of reds, blues, greens, orange, and white. For this student the colors red and blue represented the cop car lights coming to take care of a crime or situation in his environment. So for one student red and blue might be a positive thing, but for this student red and blue have a totally different and personal meaning to them. When it comes to Figure 8 (the pink bull skull with flames in the background), this student used the color pink and other warm colors to express his struggle to cope with a family member having breast cancer. In general warm colors represent warmth and light, this student decided to use warm colors to represent struggle and hope. I also noticed that some of the students went in totally different directions besides doing a close up of flowers and skulls. Some students created dream catchers, sunsets, and forests. When the project was completed and the class shared their work in the class critique, many of the students shared and responded positively to their classmates work! After the critique I went outside and sprayed preserve fixative on their pieces, and then the class went in the hallway and posted their work to be on display! This gave the school a nice pop of color 
and students from other classes would stop and look for several minutes before heading to their next class.

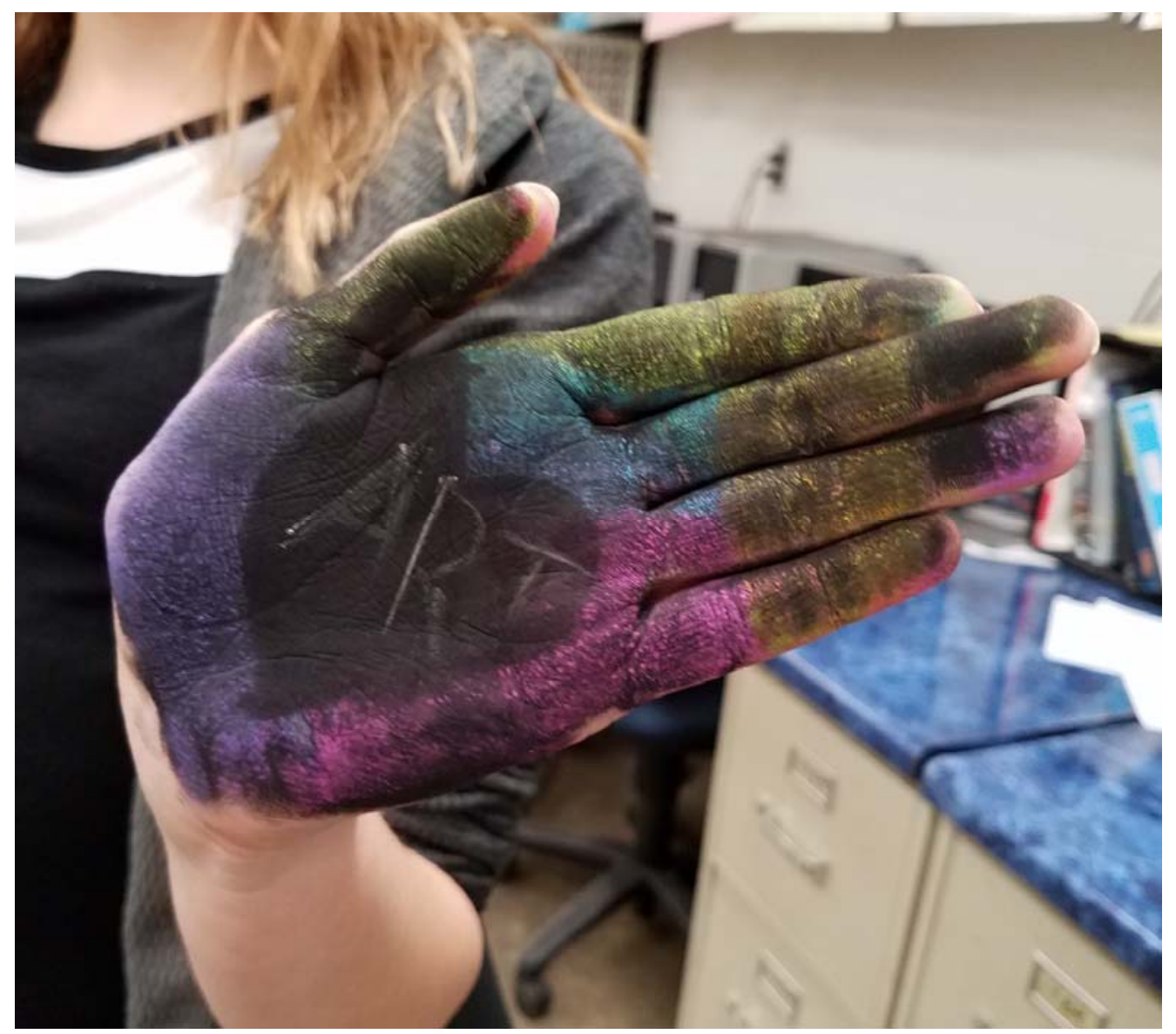

Figure 15 Site B -Students Experiments with Pastel Dust 


\subsection{Suggestions for Color Therapy Lesson}

The only flaw I witness in this lesson was sometime the students had a hard time with cleanup with the soft pastels. The colored dust would get airborne, and that may pose a problem with students that may have allergies or sensitive lungs. I suggest maybe using oil pastels if I would proceed doing this lesson again. Another great lesson using color would be letting the students paint the classroom ceiling tiles, or a class mural in the community. Another lesson that might be successful using color is exploring the art movement of abstract expressionism and the works of Mark Rothko. Like in the film "Color of Healing, 2017" we live in a gray landscape, students need a splash of color in their school in the hallways in order to have a sense of identity with their school and community.

\subsection{Site C - Action Painting Reflection and Findings}

I was extremely pleased with the results of the action painting lesson. The students had a positive reaction to the lesson. I felt as a preservice art teacher I was able to integrate art history and art therapy into this lesson. I also felt I was able to control the environment and was well organized. I was also surprised that other students quite their other classes and came out to my lesson to see what my students were doing. I felt like this lesson was done at the appropriate time, I did this lesson a couple days before finals, and many of the students were extremely stressed and overwhelmed with their classes. As I was doing the demonstrations I portrayed myself as a stressed student using body movement and art to release emotions and unwanted energy. Students would experiment with different movements and different painting tools to apply the paint. Students even experimented with folding the wet paint on paper to make symmetrical images. The 
students liked this lesson so much that they shared their experiences in the community, later a former coworker from the urban health center contacted me and she heard what I was doing at the high school. She wondered if I would do this lesson with her special needs clients. Sadly I did not have the time to do this lesson with her clients, however I feel this lesson might be something I can explore as a community art project!

\subsection{Site C - Suggestions for Action Painting}

With this lesson I felt my students were more than capable to use latex house paint, however in future lessons I will need to consider other paint mediums if a student has a latex allergies. If I was going to use latex paint again I would consider getting large sheets of canvas or heavier painting paper. The only problem we had was an environmental one-- with the wind blowing some of the art, and some paint drip's getting on the sidewalk, however, the paint was easily cleaned up and I later provided weights to use to anchor the art down so it did not blow away. This is a lesson I would do again at the end of the year in an outside environment. I felt this was an excellent lesson to show students how to use the arts in order to release stress, aggression, and other bent up emotions that the students need to expel. 


\section{CONCLUSION -SUGGESTIONS AND FUTURE RESEARCH}

Incorporating art therapy techniques and activities are so beneficial for students that

it cannot be ignored, especially when the students in West Virginia are in dire need of it in today's society. Using art as a tool for healing has deep roots in human history; however art therapy is still verily new. More research is needed when trying to use it in a public setting. Having contemporary studies done of what the psychology and social behaviors are in our students, and what social issues are going on in our students' society, I think would be crucial for today's educators. If educators have a better understanding of what the students are going through the students will relate to the teacher and form a more trusting relationship with their students. The list below is some suggestions and research idea's to incorporate art therapy in the art classroom.

1.Have several volunteer art teachers in different counties across West Virginia experiment with using art therapy activities in their classrooms. These teachers can relay their findings with the other art teachers and see if these lessons benefit their student and teacher communication. If the experiment is successful then we can do more trails with more counties until the whole state can adopt these practices in the classroom.

2.At the annual WVAEA (West Virginia Art Education Association) conference have a seminar about putting art therapy techniques and activities into art lesson to help the student and teacher relations. 
3.Form an alliance with the American Art Therapy Association, and have free classes, online resources, and text for art teachers and school counselors to use to help their students.

4. Offer more classes on art therapy and other creative therapies in colleges and universities across West Virginia.

5. Have contemporary text and teaching practices.

6. Have a stronger partnership in the art education, special education, education, and psychology departments in all universities and colleges.

7.Have art or at least a trained art educator in all high schools, middle schools, and elementary schools across the state of West Virginia.

8.Have art educators form stronger partnerships with their school counselors and local therapists in their communities.

9.Going to the West Virginia legislature and department of education to see if art educators can do more art therapy projects in their schools.

10. Study on brain wave activity while students are creating art. Seeing how the left and right hemispheres of the brain work while students are creating art. Seeing if art therapy in an art curriculum improves brain activity.

11. Offer a family and community art therapy days. This can educate West Virginians' about how the arts can benefit a better way of living. This can be a free program or limited fee, so everyone can take part in the art making process. 
Overall I believe my experience with using art therapy approaches in the classroom was life changing while I was student teaching. As I continue my journey I will experiment and find out what my student really need in order to help them with their overall well being. My hope is when my students are faced with a dark moment in their lives; they can use the tools I gave them in order to bring them into the light.

As I reflect on my experiences within the classroom and the therapy sessions I observed, I end my paper with a quote from Stephen K. Levine: "The task of therapy is not to eliminate suffering but to give a voice to it, to find a form in which it can be expressed. Expression is itself transformation; this is the message that art brings. The therapist then would be an artist of the soul, working with sufferers to enable them to find the proper container for their pain, the form in which it would be embodied" (Levine, 2017). 


\section{BIBIOGRAPHY}

(January, 1, 2012). Art Therapy \& Autism Spectrum Disorder: Integrating Creative Interventions. Retrieved July 20, 2016.

http://www.arttherapy.org/AutismToolkit/autismtoolkit.pdf

AG. Retrieved June 22, 2016, http://www.ebrary.com

Association for Play Therapy: United States. (2016). Play Therapy Makes A Difference. Retrieved April 26, 2017, from http://www.a4pt.org/?page=ptmakesadifference

Brocas, Joanna. (February, 14, 2006). History of the Chakras. Spiritual Healing Tutor Joanna Brocas.http://www.joannebrocas.com/907-2/

Brooke, S., \& Myers, C. (Eds.). (2015). The use of the creative therapies in treating depression. Springfield, Illinois: Charles C Thomas Publisher.

Buchalter, Susan I. Art Therapy Techniques and Applications. London: Jessica Kingsley, 2009.

Chakra Colors. (2017). Retrieved July 12, 2017, from http://www.chakras.info/chakracolors/

Coleman, M. B., Cramer, E. S., Park, Y., \& Bell, S. M. (23 May, 2015). Art Educators' Use of Adaptations, Assistive Technology, and Special Education Supports for Students with Physical, Visual, Severe and Multiple Disabilities. Journal of Developmental and Physical Disabilities. (27), 5, 637-660.

Color of Healing. , [San Francisco, California, USA]: Kanopy Streaming, 2016. Internet resource.http://wvu.kanopystreaming.com.www.libproxy.wvu.edu/video/colorhealing

Frank, Priscilla. (2015) How Art Therapy Can Help Children Facing Mental and Emotional Challenges. The Huffington Post. Retrieved from: http://www.huffingtonpost.com/2015/05/07/art-therapy-children

Frankish, Patricia. Disability Psychotherapy. Karnac Books, 2015. Internet resource.

Gilroy, A. (2011). Art therapy research in practice. Oxford, UKZZ: Peter Lang 
Hornby, Gary. (2014). Inclusive Special Education: Evidence-Based Practices for Children with Special Needs and Disabilities. New York, NY: Springer Publishing.

Husky, C. (2009). Art therapy, neuroscience and mind-body connection: A literature review. Alberta, Canada: Athabasca University Press.

Joseph, C. (2006). Creative Alliances: The healing power of art therapy. Art Therapy, Journal of American Art Therapy Association, 23, 30-33

Kerr, C. (2015). Multicultural Family Art Therapy. New York, NY: Routledge Taylor \& Francis.

Levine, S. K. Artz Therapy Quotes. Retrieved July, 2017, from https://artztherapy.wordpress.com/art-therapy-quotes/

NY: Taylor \& Francis, 2009. Print.

Pitt, M. (2006, June 12). Using the arts to tame Katrina's emotional force. Retrieved from:http://sparkaction.org/node/4273

Rubin, J. A. (2005). Child art therapy: 25th anniversary edition. Hoboken, NJ: John Wiley.

Rubin, Judith A. Introduction to Art Therapy: Sources \& Resources. 2nd ed. New York,

Steven, R. H., \& Stewart, E. G. (2009). Superheroes unmasked: An amazing approach to helping children learn social/emotional insights and skills. Chapin, S.C: Youth Light Inc. 
Figure 1 Elliott, Ashley. Teacher Example. 2016, watercolor and digital drawing, Site A, WV

Figure 2 Student Example, Black River.2016, watercolor. Site A, Military facility, WV Figure 3 Student Example, Ice Cream House.2016, crayon. Site A, Military facility, WV Figure 4 Student Example, Swarming Birds. 2016, watercolor. Site A, Military Facility, WV

Figure 5 Elliott, Ashley .Teacher Example Georgia O’Keeffe Color Therapy, 2017, oil pastel, Site B, WV

Figure 6 Elliott, Ashley. Blending Technique Example. 2017, soft pastel, Site B, WV Figure 7 Student Example. Rose with Cop Car Lights, 2017, soft pastel, Site B, WV Figure 8 Student Example. Breast Cancer Bull Skull, 2017, soft pastel, Site B, WV Figure 9 Student Example. Lack of Color, 2017, soft pastel, Site B, WV Figure 10 Elliott, Ashley, Action Painting Teacher Display Board, 2017, mix media, Site C, WV

Figure 11 Student Example. Experiment Blending Drips, 2017, latex painting, Site C, WV

Figure 12 Student Example. Student Experiment with Controlled Movements, 2017, latex painting, Site C, WV

Figure 13 Students Examples, 2017, latex paintings, Site C, WV

Figure 14 Coloring Activity, 2017, coloring pencil, Site D, WV Figure 15 Student Example. Student Experiments with Pastel Dust, 2017 soft pastel on skin, Site B, WV 
